\section{Pacific Northwest}

\section{National Laboratory}

Operated by Battelle for the

U.S. Department of Energy

\title{
Natural and Enhanced Attenuation of Chlorinated Solvents Using RT3D
}

C. D. Johnson

M. J. Truex

T.P. Clement

July 2006

Prepared for the U.S. Department of Energy under Contract DE-AC05-76RL01830 


\title{
DISCLAIMER
}

This report was prepared as an account of work sponsored by an agency of the United States Government. Neither the United States Government nor any agency thereof, nor Battelle Memorial Institute, nor any of their employees, makes any warranty, express or implied, or assumes any legal liability or responsibility for the accuracy, completeness, or usefulness of any information, apparatus, product, or process disclosed, or represents that its use would not infringe privately owned rights. Reference herein to any specific commercial product, process, or service by trade name, trademark, manufacturer, or otherwise does not necessarily constitute or imply its endorsement, recommendation, or favoring by the United States Government or any agency thereof, or Battelle Memorial Institute. The views and opinions of authors expressed herein do not necessarily state or reflect those of the United States Government or any agency thereof.

\author{
PACIFIC NORTHWEST NATIONAL LABORATORY \\ operated by \\ BATTELLE \\ for the \\ UNITED STATES DEPARTMENT OF ENERGY \\ under Contract DE-AC05-76RL01830 \\ Printed in the United States of America \\ Available to DOE and DOE contractors from the \\ Office of Scientific and Technical Information, \\ P.O. Box 62, Oak Ridge, TN 37831-0062; \\ ph: (865) 576-8401 \\ fax: (865) 576-5728 \\ email: reports@adonis.osti.gov
}

\begin{abstract}
Available to the public from the National Technical Information Service, U.S. Department of Commerce, 5285 Port Royal Rd., Springfield, VA 22161 ph: (800) 553-6847 fax: (703) 605-6900

email: orders@ntis.fedworld.gov

online ordering: http://www.ntis.gov/ordering.htm
\end{abstract}

This document was printed on recycled paper. 


\title{
Natural and Enhanced Attenuation of Chlorinated Solvents Using RT3D
}

\author{
C. D. Johnson \\ M. J. Truex \\ Pacific Northwest National Laboratory \\ TP Clement \\ Auburn University
}

July 2006

Prepared for

the U.S. Department of Energy

under Contract DE-AC05-76RL01830

Pacific Northwest National Laboratory

Richland, Washington 99352 



\section{Summary}

RT3D (Reactive Transport in 3-Dimensions) is a reactive transport code that can be applied to model solute fate and transport for many different purposes. This document specifically addresses application of RT3D for modelling related to evaluation and implementation of Monitored Natural Attenuation (MNA). Selection of MNA as a remedy requires an evaluation process to demonstrate that MNA will meet the remediation goals. The United States Environmental Protection Agency, through the Office of Solid Waste and Emergency Response (OSWER) Directive 9200.4-17P, provides the regulatory context for the evaluation and implementation of MNA. In a complementary fashion, the context for using fate and transport modelling as part of MNA evaluation is described in the EPA's technical protocol for chlorinated solvent MNA, the Scenarios Evaluation Tool for Chlorinated Solvent MNA, and in this document. The intent of this document is to describe 1) the context for applying RT3D for chlorinated solvent MNA, 2) the attenuation processes represented in RT3D, 3) dechlorination

reactions that may occur, and 4) the general approach for using RT3D reaction modules (including a summary of the RT3D reaction modules that are available) to model fate and transport of chlorinated solvents as part of MNA (potentially in combination with selected types of active remediation). 


\section{Acknowledgments}

This document is a product of the Monitored Natural Attenuation / Enhanced Attenuation for Chlorinated Solvents Technology Alternative Project (MNA/EA Alternative Project). The MNA/EA Alternative Project was sponsored by the U.S. Department of Energy (DOE) Office of Cleanup Technologies and administered by the U.S. Department of Energy Savannah River (SR) Operations Office. The authors appreciate the guidance and support of Claire H. Sink of DOE Headquarters and Karen M. Adams of DOE SR. The authors thank Brian Looney and Karen Vangelas of Savannah River National Laboratory and the MNA/EA Alternative Project Technical Working Group for their review and feedback on the work documented here. 


\section{Contents}

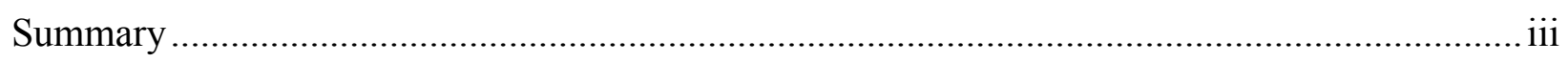

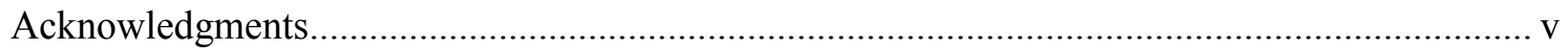

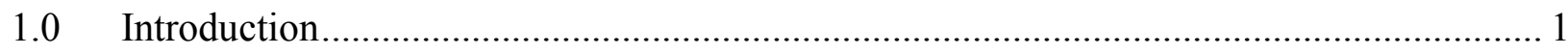

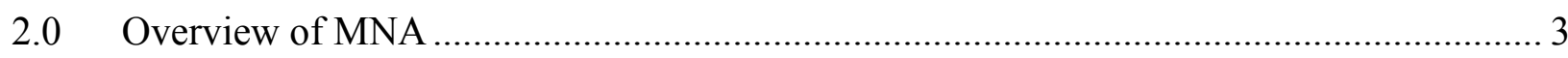

3.0 Overview of Reactive Transport Modelling for MNA …………..................................... 5

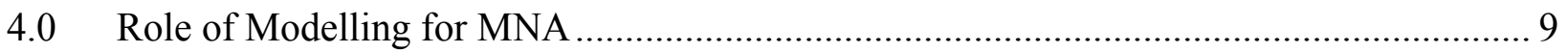

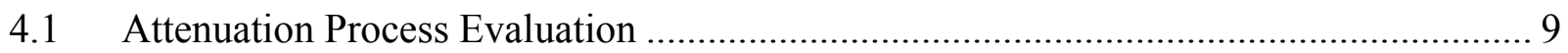

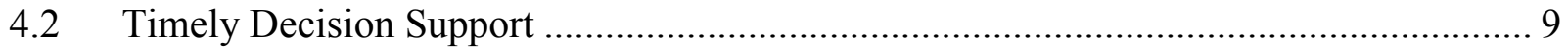

4.3 Transition to MNA from Other Remedies …………............................................... 10

4.4 Evaluating Combinations of MNA and EA or Other Remedies ................................... 11

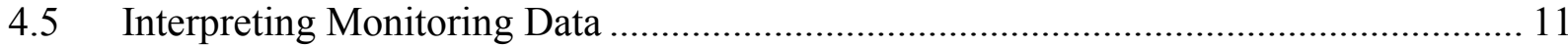

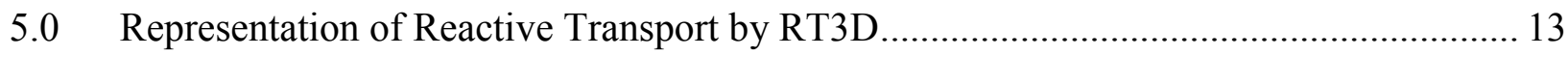

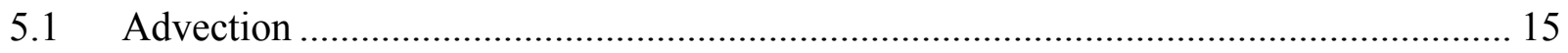

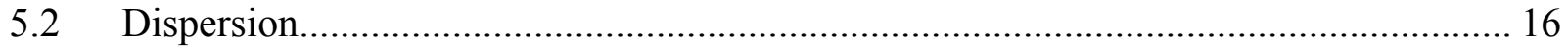

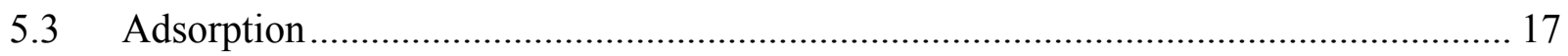

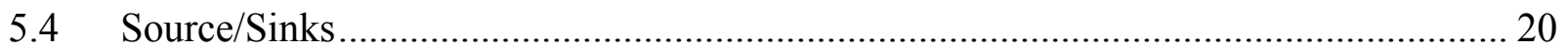

5.4.1 NAPL-Water Mass Transfer............................................................................... 20

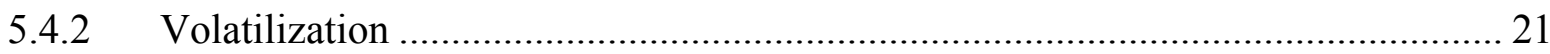

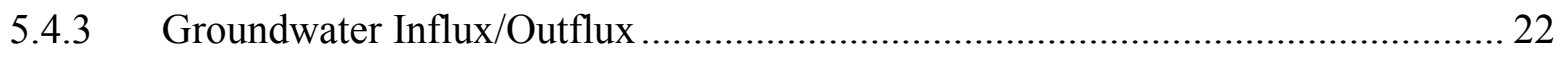

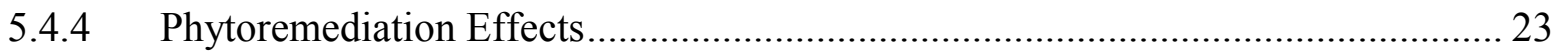

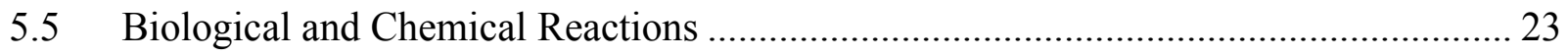

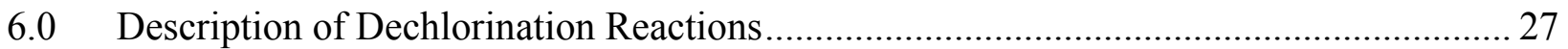

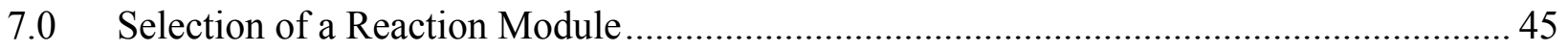

8.0 Using a Reaction Module........................................................................................... 49

8.1 Understanding Site Characteristics With Respect To Reaction Processes That May Be Occurring. 


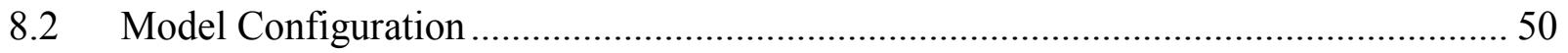

8.2.1 Determining Reaction Parameter Values........................................................... 50

8.2.2 Determining Whether the Reaction Parameter Values Need to be

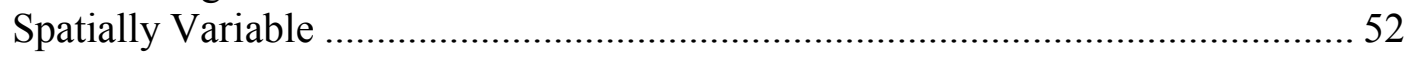

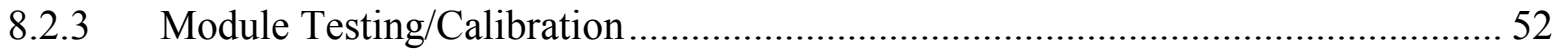

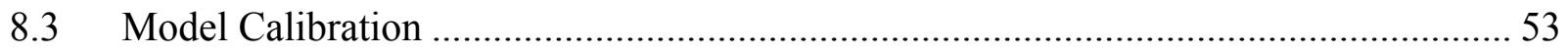

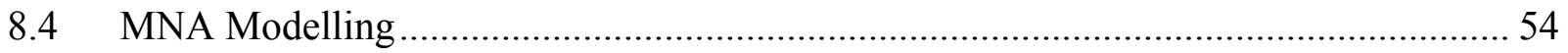

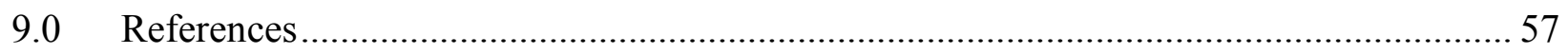

9.1 Numbered References Cited in Reaction Pathway Figures ………………………...... 57

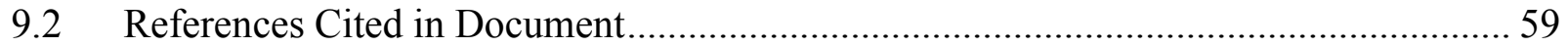




\section{Figures}

1 Mass Transfer Concept at the Groundwater Table Interface .......................................... 22

2 Dechlorination Reactions for PCE under the Aerobic Geochemical Setting .................... 31

3 Dechlorination Reactions for PCE under the Anoxic Geochemical Setting..................... 32

4 Dechlorination Reactions for PCE under the Anaerobic Geochemical Setting.................. 33

5 Dechlorination Reactions for 1,1,2,2-TeCA under the Aerobic Geochemical Setting....... 34

6 Dechlorination Reactions for 1,1,2,2-TeCA under the Anoxic Geochemical Setting........ 35

7 Dechlorination Reactions for 1,1,2,2-TeCA under the Anaerobic Geochemical Setting.... 36

8 Dechlorination Reactions for 1,1,1,2-TeCA under the Aerobic Geochemical Setting........ 37

9 Dechlorination Reactions for 1,1,1,2-TeCA under the Anoxic Geochemical Setting......... 38

10 Dechlorination Reactions for 1,1,1,2-TeCA under the Anaerobic Geochemical Setting.... 39

11 Dechlorination Reactions for CT under the Aerobic Geochemical Setting...................... 40

12 Dechlorination Reactions for CT under the Anoxic Geochemical Setting....................... 41

13 Dechlorination Reactions for CT under the Anaerobic Geochemical Setting.................. 42

14 Flowchart for Selection of RT3D Reaction Modules for MNA/EA ................................ 45

\section{Tables}

1 Considerations for Selecting a Modelling Approach Based on Site Properties................... 6

2 Chlorinated Contaminant Species by Contaminant Type .............................................. 28

3 Descriptions of Biological and Abiotic Dechlorination Reactions ................................. 29

4 Additional Characterization Information to Assess Whether a Reaction Will Occur ......... 43

5 Description of the RT3D Reaction Modules for MNA/EA …...................................... 46

6 Criteria for Selecting the Geochemical Setting ..................................................... 50 


\subsection{Introduction}

RT3D (Reactive Transport in 3-Dimensions) [Clement, 1997; Clement et al., 1998, Clement and Johnson, 2002] is a reactive transport code that can be applied to model solute fate and transport for many different purposes. This document specifically addresses application of RT3D for modelling related to evaluation and implementation of Monitored Natural Attenuation (MNA). Selection of MNA as a remedy requires an evaluation process to demonstrate that MNA will meet the remediation goals. The United States Environmental Protection Agency (U.S. EPA), through the Office of Solid Waste and Emergency Response (OSWER) Directive 9200.4-17P [U.S. EPA, 1999a], provides the regulatory context for the evaluation and implementation of MNA. In a complementary fashion, the context for using fate and transport modelling as part of MNA evaluation is described in the EPA's technical protocol for chlorinated solvent MNA [U.S. EPA, 1998], the Scenarios Evaluation Tool for Chlorinated Solvent MNA [Truex et al., 2006], and in this document. The intent of this document is to describe 1) the context for applying RT3D for chlorinated solvent MNA, 2) the attenuation processes represented in RT3D, 3) dechlorination reactions that may occur, and 4) the general approach for using RT3D reaction modules (including a summary of the RT3D reaction modules that are available) to model fate and transport of chlorinated solvents as part of MNA or for combinations of MNA and selected types of active remediation.

This document provides the following information related to applying RT3D for chlorinated solvent MNA. Section 2.0 is an overview of MNA. In Section 3.0, an overview of reactive transport modelling for MNA is presented. Section 4.0 provides a discussion of specific roles for modelling as part of MNA evaluation and implementation. A description of how RT3D models reactive transport is presented in Section 5.0. In Section 6.0, the specific reactions for the chlorinated species that are included in the RT3D reaction modules for MNA are described. Section 7.0 discusses how to select the RT3D reaction module based on contaminants and the type of modelling that is required at the site. Section 8.0 describes the process for applying a reaction module for fate and transport modelling. 


\subsection{Overview of MNA}

Monitored Natural Attenuation is an environmental management strategy that relies on a variety of attenuation processes to degrade or immobilize contaminants and is implemented at appropriate sites by demonstrating that contaminant plumes have low risk and are either stable or shrinking. The U.S. EPA "Use of Monitored Natural Attenuation at Superfund, RCRA Corrective Action, and Underground Storage Tank Sites" OSWER Directive [U.S. EPA, 1999a], hereafter referred to as the "OSWER MNA Directive," is the primary document describing the regulatory context for MNA. The natural attenuation (NA) processes recognized in the OSWER MNA Directive are delineated in the following quotation [U.S. EPA, 1999a, page 3].

The "natural attenuation processes" that are at work in such a remediation approach [MNA] include a variety of physical, chemical, or biological processes that, under favorable conditions, act without human intervention to reduce the mass, toxicity, mobility, volume, or concentration of contaminants in soil or groundwater. These in-situ processes include biodegradation; dispersion; dilution; sorption; volatilization; radioactive decay; and chemical or biological stabilization, transformation, or destruction of contaminants.

The OSWER MNA Directive outlines a three-tiered approach that has generally been used for evaluating the suitability of MNA as a remedy. This approach includes use of:

1. Historical groundwater and/or soil chemistry data that demonstrate a clear and meaningful trend of decreasing contaminant mass and/or concentration over time at appropriate monitoring or sampling points. (In the case of a groundwater plume, decreasing concentrations should not be solely the result of plume migration. In the case of inorganic contaminants, the primary attenuating mechanism should also be understood.)

2. Hydrogeologic and geochemical data that can be used to demonstrate indirectly the type(s) of natural attenuation processes active at the site, and the rate at which such processes will reduce contaminant concentrations to required levels. (For example, characterization data may be used to quantify the rates of contaminant sorption, dilution, or volatilization, or to demonstrate and quantify the rates of biological degradation processes occurring at the site.)

3. Data from field or laboratory microcosm studies (conducted in or with actual contaminated site media) which directly demonstrate the occurrence of a particular natural attenuation process at the site and its ability to degrade the contaminants of concern (typically used to demonstrate biological degradation processes only).

Specific steps for determining whether MNA can meet remediation goals for chlorinated solvents are provided in the Technical Protocol for Evaluating Natural Attenuation of Chlorinated Solvents in Ground Water [U.S. EPA, 1998], referred to here as the "EPA MNA Protocol." 
Briefly, this protocol outlines data and analysis requirements that include 1) site characterization, 2) an initial screening assessment to verify that site conditions are consistent with the conditions needed for NA processes, 3) developing "lines of evidence" that NA is occurring, and 4) demonstrating (e.g., through fate and transport modelling) that NA is likely to mitigate plume migration and meet remediation goals. If MNA is selected as the remedy, it is implemented using a monitoring plan designed to verify that NA processes continue to attenuate the plume and that remediation goals are met over time.

The Scenarios Evaluation Tool for Chlorinated Solvent MNA [Truex et al., 2006] provides a framework that links the MNA evaluation and associated decision logic to key site characteristics and known natural attenuation phenomena. The approach is to take the wide spectrum of chlorinated solvent sites (e.g., different sources, hydrogeology, geochemistry, degradation process) and sort them into one of 13 different MNA scenarios. By applying a taxonomic system, users can determine which scenario best describes their plume (or a segment of their plume). Each scenario contains information about how to proceed with MNA evaluation for the type of plumes that fit within the scenario. The approach includes information to determine when numerical modelling may be needed as part of the MNA evaluation process.

MNA may be a viable single remedy for the site. However, if it is determined that MNA may not meet remediation goals, Enhanced Attenuation (EA) approaches may be considered. The EA approach is to use a remediation technology that is a sustainable enhancement to natural attenuation either through reduction of source flux (loading) to the plume or through enhancing the attenuation processes. More aggressive source control may also be necessary for sites where incremental enhancements alone are unlikely to be sufficient.

EA approaches can be categorized by the different zones to which they are applied: source zone (reduction of contaminant mass flux to plume); plume (enhanced attenuation processes); or discharge zone (enhanced attenuation processes). Within the source zone, enhancements can be applied as a hydraulic manipulation or as a passive source reduction. Within the plume and discharge zone, either biological (microbial or plant based) or abiotic (abiotic degradation, reactive barriers, sorption) attenuation processes can be enhanced. More detailed information about EA technologies is available in Early et al. [2006].

Source control actions include active remediation of the source area through biological or chemical remediation processes (e.g., bioremediation, thermal treatment, chemical oxidation, solvent flushing) or active containment approaches such as pump-and-treat. These actions are more active/aggressive source reduction and containment approaches, which may be needed for strong source areas that have a significant mass of contamination feeding the plume. 


\subsection{Overview of Reactive Transport Modelling for MNA}

The concept of a mass balance between the loading and attenuation of contaminants in a groundwater system provides a framework for conceptualizing and documenting the relative stability of a contaminant plume. Thus, a mass balance concept has significant potential to support appropriate implementation of MNA or EA. For a mass balance to be useful in engineering practice, however, it is necessary to quantify it in practical ways that facilitate overall site remediation and which are consistent with existing regulatory guidance. Fate and transport modelling can be used for implementing this type of plume analysis and providing a technical basis for evaluating MNA as a remedy when simpler evaluations are not suitable.

The type of model applied at a specific site is dependent on the site conditions and the intended use of the model. The discussion here is limited to models for solute transport under saturated conditions. In addition to the conceptual model, which is a necessary part of any site evaluation, two basic levels of models that are relevant to MNA modelling are available. Analytical models (e.g., BIOCHLOR [U.S. EPA, 1999b] or ART3D [Quezada et al., 2003]) are capable of solving the general transport equation with specific limitations. Three-dimensional multi-species reactive transport numerical models, such as RT3D, discretize the transport equation and iteratively solve it within a defined numerical domain. As such, RT3D allows for more detailed configuration of the model domain to more closely match site features. Selection of the appropriate level of model for a specific site is dependent on the site conditions and configuration-related differences between analytical models and numerical models. Table 1 provides a brief overview of considerations for selecting the primary type of modelling analysis based on site properties, in particular based on whether the geochemistry and hydrology of the site readily supports a relatively simple description of attenuation and transport processes or whether the geochemistry and hydrology are complex. Other considerations for model selection are discussed below.

BIOCHLOR [U.S. EPA, 1999b] and ART3D [Quezada et al., 2003 and 2004; Clement, 2001] are analytical models that have been established specifically for use in modelling MNA. For analytical models, the solution technique typically requires assumptions of uniform hydraulic properties throughout the domain, uniform steady-state groundwater flow (in some case limited to one-dimensional advection), simple boundary conditions, simple source geometry, first-order contaminant transformation with rates constant within a defined area (in some cases for a single decay pathway), and uniform linear equilibrium partitioning. Analytical models can be useful in providing estimates of contaminant migration for plumes where these assumptions can be technically supported based on the site conditions. For instance, consider a plume with a welldefined contaminant source of TCE within a relatively homogeneous, thin aquifer that is bounded by aquitards or by an aquitard and the water table and where the aquifer has relatively constant methanogenic conditions throughout the plume. In this case, the assumptions required for use of an analytical model are appropriate. 
Table 1. Considerations for Selecting a Modelling Approach Based on Site Properties

\begin{tabular}{|c|c|c|c|c|c|}
\hline \multirow[b]{2}{*}{$\begin{array}{l}\text { Modelling } \\
\text { Approach }\end{array}$} & \multicolumn{2}{|c|}{$\begin{array}{c}\text { Sites with supportive } \\
\text { geochemical / hydrologic } \\
\text { conditions }\end{array}$} & \multicolumn{3}{|c|}{$\begin{array}{l}\text { Sites with hydrologic and / or } \\
\text { geochemical complexity / challenges }\end{array}$} \\
\hline & $\begin{array}{l}\text { Simple site with } \\
\text { stable or } \\
\text { shrinking plume }\end{array}$ & $\begin{array}{l}\text { Plume stability } \\
\text { \& geochemical } \\
\text { footprints } \\
\text { uncertain }\end{array}$ & $\begin{array}{l}\text { Documented plume } \\
\text { growth or outcrop or } \\
\text { perturbed - may be } \\
\text { stable in the future }\end{array}$ & $\begin{array}{c}\text { Geochemical } \\
\text { conditions uncertain } \\
\text { and/or complex } \\
\text { hydrologic conditions }\end{array}$ & $\begin{array}{l}\text { Attenuation } \\
\text { Process } \\
\text { Enhancement } \\
\text { Evaluation }\end{array}$ \\
\hline $\begin{array}{l}\text { Conceptual Model - } \\
\text { Identify contributing } \\
\text { processes and the } \\
\text { active zones within } \\
\text { a plume. }\end{array}$ & 0 & 0 & [2] & & [2] \\
\hline $\begin{array}{l}\text { Conceptual Model } \\
\text { plus Analytical } \\
\text { Model or Mass } \\
\text { Balance Calculation }\end{array}$ & 0 & 0 & 0 & 0 & 0 \\
\hline $\begin{array}{l}\text { Conceptual Model, } \\
\text { possible Analytical } \\
\text { Model, and } \\
\text { Numerical Model }\end{array}$ & ${ }^{[1]}$ & 0 & 0 & 0 & 0 \\
\hline \multicolumn{6}{|c|}{$\begin{array}{l}\text { NOTES: } \\
\text { Numerical modelling is not necessarily preferred because costs may not be justifiable for } \\
\text { the offsetting benefits in terms of uncertainty reduction, monitoring optimization, etc. } \\
\text { However, numerical models may be selected if it is necessary to provide better estimates } \\
\text { of time frames and better assurance of meeting certain types of remediation goals (e.g., } \\
\text { concentration targets) than can be obtained with analytical modelling. }\end{array}$} \\
\hline
\end{tabular}

RT3D numerical modelling is needed when site conditions cannot be described under the simplified flow, reaction, or adsorption process assumptions that are required for use of analytical models. The groundwater flow system at a site may not be uniform because of a complex distribution of hydraulic conductivity, complex recharge/discharge elements, or transient flow conditions. Sources distributed in multiple locations, multiple contaminant species with multiple reaction pathways, and multiple oxidation/reduction conditions within the plume area cause complexities in modelling the reaction processes at a site. In some cases, assumption of linear equilibrium sorption is not appropriate, depending on the nature of the contaminant and the aquifer solids. For site conditions that include any or all of these complexities, RT3D is a more appropriate tool for modelling than use of analytical models.

Similar to analytical models, RT3D has some limitations in how it can be configured to match site conditions. A discrete numerical model cannot describe all of the nuances for each term within the transport equation. That is, RT3D cannot exactly reproduce reality because of 
limitations in representing effects of the reactive transport processes at multiple scales and/or because our understanding of the processes is limited. However, compared to analytical models, RT3D can be configured to more closely match the site conditions and processes. In addition, there are also limitations in the type and quality/quantity of data that are available at any site to develop the parameters/coefficients required for the equations solved by RT3D.

A numerical model (e.g., using RT3D) can provide information to help analyze the relative importance of different fate and transport processes at an individual site and assess the plume in terms of a mass balance approach. The model can also be used to estimate the future fate and transport of contaminants. These predictions can be valuable input, along with other site information, in making timely decisions regarding implementation of remedial actions or for planning monitoring activities. A key function of the predictive capability of models is to estimate whether the remedy will meet the remediation goals when this determination cannot be made directly with field data. Numerical models, in particular, have the computational ability to estimate the interaction of multiple processes temporally and spatially for scenarios that would be difficult to assess with analytical methods. 


\subsection{Role of Modelling for MNA}

The analysis and predictive functions of modelling are important within the context of applying MNA to 1) help analyze the relative importance of different attenuation and transport processes within a plume, 2) provide timely decision support, for instance, when there is insufficient temporal monitoring data available, 3) evaluate MNA as a remedy to replace existing remedies (e.g., P\&T) that have perturbed the plume such that data to establish whether the plume is stable will not be available for a long time, 4) evaluate combinations of other remedial actions (e.g., Enhanced Attenuation) and MNA, and 5) help interpret monitoring data for transient plumes.

There are two basic capabilities of RT3D that can be applied for multiple purposes in applying MNA. The first capability is to estimate the interaction of multiple processes for fate and transport of contaminants. RT3D can also estimate the future fate and transport of contaminants and, in particular, estimate whether the MNA or MNA/EA remedy will meet remediation goals. The following sections describe these capabilities within specific roles of MNA modelling.

\subsection{Attenuation Process Evaluation}

RT3D can be used to assess the relative importance of attenuation processes under the specific conditions of a site. The natural attenuation capacity of the aquifer is defined as the sum of the processes that are active within the aquifer being evaluated. The rate of these processes is a function of contaminant concentration and other parameters that can vary spatially and, in some cases, temporally. Modelling analysis of these processes can provide a quantitative basis for refining the conceptual model of the site.

As a simplification, the capacity of each process to attenuate contamination can be calculated using averaged conditions for the site or for distinct portions of the site. However, to assess how these attenuation processes impact fate and transport of the contamination, the processes must be coupled and solved within a transport equation.

\subsection{Timely Decision Support}

If sufficient field data are not available to determine directly whether MNA will meet remediation goals, modelling, with appropriate input to describe the attenuation processes at the site, can be used to estimate whether the goals can be met. The modelling estimate and other relevant attenuation evidence provide the basis for a decision on whether to implement MNA. Continued monitoring can then be applied to verify whether the plume is behaving as expected and that remediation goals are met over time.

Example: Site "A" received waste petrochemical liquids from 1962 through 1973 in an open pit. The waste pit leaked dense non-aqueous-phase liquid (DNAPL) into a thin, moderately permeable, silt/sand unit in the subsurface where the groundwater is relatively stagnant. DNAPL contamination at the site is confined to this unit. However, the groundwater of this unit slowly 
flows into a deeper sandy paleo-channel through several hydraulic conduits in the intervening clay that separates the upper silt/sand unit from the paleo-channel. Over the forty years since the waste was initially disposed of, a dissolved-phase plume of the more soluble chlorinated ethene and chlorinated ethane compounds in the waste has developed in this channel. Characterization data were collected for the plume over a period of about 5 years. The U.S. EPA MNA Protocol [U.S. EPA, 1998] was applied at the site and it was determined that there are significant attenuation processes active. However, it was not clear from the data whether the plume was stable or shrinking.

A numerical model was used to evaluate migration of the plume toward the identified receptors. Based on the modelling results and the evidence that there are significant attenuation processes at the site, MNA was approved as the remedy for the site. Monitoring is being conducted to ensure that remediation goals are met and to verify that the attenuation processes are effectively limiting plume migration. While there was not direct field evidence that the plume was currently stable or shrinking at this site, the regulatory agencies were able to support an MNA remedy based on the model predictions, the lack of risk to receptors in the near future, and the ability to effectively use monitoring to verify the MNA remedy in the near future as more data is collected to establish the trends needed to evaluate stability of the plume.

\subsection{Transition to MNA from Other Remedies}

For sites where another remedy is in place, the transition to MNA may require assessment of a transient plume with respect to whether MNA will be able to meet remediation goals over time. For instance, if Pump-and-Treat (P\&T) is being applied to all or a portion of a plume, there will not be direct field evidence available to support a decision to transition to MNA. However, along with data to quantify the attenuation capacity, numerical modelling can be applied to predict how the plume will respond if P\&T is shut down. Continued monitoring can then be used to verify whether the plume is behaving as expected and that remediation goals are met over time.

Example: Site "B" received waste petrochemical liquids from 1969 through 1980 in open pits. DNAPL migrated from the waste pits into the subsurface below the water table within alluvial deposits. Free-phase DNAPL was discovered in the subsurface during site characterization. Because the free-phase DNAPL still had the potential to migrate as a non-aqueous phase, recovery wells were installed and DNAPL extraction was initiated. In addition to direct DNAPL extraction, the DNAPL source area was surrounded by groundwater extraction wells designed to contain the dissolved-phase plume emanating from the source area and to depress the water table, in theory, to help limit vertical migration of the DNAPL. After about 5 years of operation, it was determined that the groundwater extraction was not needed to limit vertical migration of the DNAPL. The site then desired to evaluate natural attenuation as a means to limit migration

of the dissolved-phase plume to protect the downgradient receptors so that groundwater extraction could be terminated. 
The U.S. EPA MNA Protocol [U.S. EPA, 1998] was applied at the site and it was determined that there are significant attenuation processes active. A numerical model was used to estimate how the plume would migrate after the extraction wells were shut down. The modelling results indicated that the plume is expected to become stable within about 20 years, remain within the site property line, and not impact any receptors. The EPA approved MNA as the remedy for the dissolved-phase plume at the site and the groundwater extraction wells were shut down. Monitoring is being conducted to ensure that remediation goals are met and to verify that the attenuation processes are effectively limiting plume migration.

\subsection{Evaluating Combinations of MNA and EA or Other Remedies}

In some cases, MNA alone may not be able to meet remediation goals. EA may be a candidate to use in conjunction with MNA to meet these goals. However, to determine how to combine these remedies requires selecting the appropriate EA, determining performance goals for the EA, and assessing how the conditions created by the EA action will impact the natural attenuation processes. Numerical modelling can aid in this process by evaluating different scenarios for applying combined MNA/EA remedies.

For instance, if a plume is growing and it is not expected that natural attenuation processes can stabilize the plume before receptors are impacted, MNA can still be a component of the remediation strategy for the plume by 1) coupling MNA with another technology that can augment the natural attenuation capacity of the plume or 2) removing enough contaminant mass such that the natural attenuation capacity of the aquifer is sufficient to stabilize the plume. The role of numerical modelling in this case would be to aid in evaluating different combinations of technologies with MNA.

\subsection{Interpreting Monitoring Data}

Interpretation of monitoring data for MNA includes assessing whether natural attenuation processes are continuing to occur as expected. For plumes that are not at steady state but for which MNA was selected because the plume was predicted to reach steady state before impacting receptors, assessing the natural attenuation processes can be conducted, in part, by comparing the actual temporal changes in the plume to the model-predicted temporal changes in the plume.

Example: Site "B" (Section 4.3) had used P\&T for containment of the dissolved-phase chlorinated solvent plume. Based on predictive modelling and knowledge of existing attenuation processes, the EPA approved MNA as the remedy for the dissolved-phase plume at the site and the extraction wells were shut down.

Monitoring is being conducted to ensure that remediation goals are met and to verify that the attenuation processes are effectively limiting plume migration. The model results include 
concentration profiles as a function of time for each contaminant species in the dissolved-phase contaminant plume. Because the source area was hydraulically contained for about 6 years, contaminant concentrations downgradient of the source area were expected to increase after the groundwater extraction was stopped over a period of about 20 years before stabilizing. However, the concentrations are expected to increase at a rate that is much lower than would be observed if no natural attenuation occurred.

Contaminant concentration profiles are expected to follow a specific pattern based on the degradation processes observed in site-specific microcosm tests. If the actual contaminant plume is to become stable, the concentration profiles of each contaminant species should be similar to the profiles predicted by the model. Thus, the monitoring plan uses a comparison of predicted concentration profiles to measured concentration profiles to evaluate the performance of the selected MNA remedy. In the plan, three simulated concentration time profiles along a transect of the plume were developed using the model. One time profile is based on the model prediction using the natural attenuation rates that best matched the site data (baseline). Another time profile is based on a model prediction using biological natural attenuation rates that are $10 \%$ of the baseline rates. The third time profile is based on model predictions with biological natural attenuation rates set to zero. Because the concentration profile of contaminants downgradient of the source depend significantly on the magnitude of the biological natural attenuation processes, comparison of measured and predicted concentrations along a transect is considered to be an acceptable verification of whether these processes are occurring as expected. The monitoring plan outlines how the field data collected over time at this transect will be compared to these three simulated profiles. If the field data is most similar to the baseline natural attenuation simulated profile, monitoring is continued. If the field data is most similar to either of the other two simulated profiles, the MNA remedy must be re-evaluated and, potentially, contingency actions may need to be implemented. 


\subsection{Representation of Reactive Transport by RT3D}

This section outlines how RT3D is configured for modelling reactive transport. The configuration of a numerical model must be tailored to the specific site based on the conceptual model, site hydraulic and reaction/geochemical data, and remediation goals.

RT3D provides a solution technique for the contaminant transport equation. Configuration of the model consists of determining the appropriate equation terms and setting the spatial and temporal context for solving the relevant equations. The governing equation for three-dimensional, multispecies transport in saturated porous media for constant porosity is shown in Equation 1 (adapted from Zheng and Wang [1999]). This equation shows the combination of all of the attenuation processes that contribute to the mass balance: dispersion/diffusion, advection, external sources/sinks, adsorption, and reaction. Equation 1 is a generalized form and it may be necessary to add terms (i.e., as terms of the reaction component) to describe other processes (e.g., the dissolution rate of non-aqueous phase liquid, contaminant exchange with the vadose zone, plant uptake) at a specific site.

$$
\begin{aligned}
& \begin{array}{l}
\text { rate of } \\
\text { change + adsorption }
\end{array}=\text { dispersion } \\
& \frac{\partial C_{k}}{\partial t}+\frac{\rho_{b}}{\theta} \frac{\partial \hat{C}_{k}}{\partial t}=\frac{\partial}{\partial x_{i}}\left(D_{i j} \frac{\partial C_{k}}{\partial x_{j}}\right)-\frac{\partial\left(v_{i} C_{k}\right)}{\partial x_{i}}+\frac{q_{s}}{\theta} C_{s, k}+\frac{1}{\theta} \sum r_{k}
\end{aligned}
$$

In Equation $1, C_{k}$ is the concentration of the $k^{\text {th }}$ species $\left(M / L^{3}\right), t$ is time $(T), D_{i j}$ is the hydrodynamic dispersion coefficient tensor $\left(\mathrm{L}^{2} / \mathrm{T}\right), \mathrm{x}_{\mathrm{i}}$ is the distance along the respective axis of the coordinate system $(\mathrm{L}), \mathrm{v}_{\mathrm{i}}$ is the linear pore water velocity $(\mathrm{L} / \mathrm{T}), \mathrm{q}_{\mathrm{s}}$ is the volumetric flow rate of sources (positive) or sinks (negative) per unit volume of aquifer $\left(\mathrm{L}^{3} / \mathrm{T}\right), \mathrm{C}_{\mathrm{s}, \mathrm{k}}$ is the concentration of the $\mathrm{k}^{\text {th }}$ species in the sources or sinks $\left(\mathrm{M} / \mathrm{L}^{3}\right), \theta$ is the porosity of the aquifer $\left(\mathrm{L}^{3} / \mathrm{L}^{3}\right), \rho_{\mathrm{b}}$ is the dry bulk density of the subsurface sediments $\left(\mathrm{M} / \mathrm{L}^{3}\right), \hat{\mathrm{C}}_{\mathrm{k}}$ is the concentration of the $\mathrm{k}^{\text {th }}$ species on the solid phase $(\mathrm{M} / \mathrm{M})$, and $\mathrm{r}_{\mathrm{k}}$ represents the reaction terms for transformation of the $\mathrm{k}^{\text {th }}$ species $\left(\mathrm{M} / \mathrm{L}^{3} / \mathrm{T}\right)$. Units are specified generically as $\mathrm{M}=$ mass, $\mathrm{L}=$ length, and $\mathrm{T}=$ time. Note that the linear pore water velocity times the porosity is equal to the specific discharge (Darcy flux). The reaction term $r_{k}$ may be comprised of multiple terms to account for the specific reactions occurring.

RT3D obtains groundwater flow velocities from a separate flow model, typically the MODFLOW code [Harbaugh et al., 2000] with the LMT package [Zheng et al., 2001] active. Saturated groundwater flow velocities are calculated from the hydraulic-head values that are computed by MODFLOW. The flow equations used are [Zheng and Wang, 1999]:

$$
v_{i}=-\frac{K_{i}}{\theta} \frac{\partial h}{\partial x_{i}}
$$




$$
S_{s} \frac{\partial h}{\partial t}=\frac{\partial}{\partial x_{i}}\left(K_{i} \frac{\partial h}{\partial x_{i}}\right)+q_{s}
$$

In addition to previously defined variables, $\mathrm{K}_{\mathrm{i}}$ is the principal component of the hydraulic conductivity tensor $(\mathrm{L} / \mathrm{T}), \mathrm{h}$ is the hydraulic head $(\mathrm{L})$, and $\mathrm{S}_{\mathrm{s}}$ is the specific storage coefficient $(1 / \mathrm{L})$ in equations 2 and 3.

To provide meaningful results, initial and boundary conditions must be established for a model based on actual physical site conditions. Initial conditions are the starting values of species concentrations (or hydraulic head for MODFLOW). Types of transport boundary conditions include defined concentrations for model boundary cells, distributed sources (e.g., recharge), and/or point sources (e.g., wells, rivers, drains, etc.).

There are specific calculation- and discretization-related errors that are inherent to solving the transport equation with numerical models. Within a numerical solution, there are tolerances for solutions, stability constraints, mass balance issues, and time-step constraints that need to be considered the numerical model setup. Numerical dispersion for solute transport, the artificial spreading of solutes to adjacent grid cells, can also be problematic for some solution techniques under conditions where the ratio of advection-related transport to dispersion-related transport is large. The MT3DMS manual [Zheng and Wang, 1999] provides a good discussion of the issues involved with artificial oscillation and numerical dispersion resulting from the advection solution procedure and model setup. Users should follow the MT3DMS guidance for appropriate values of the Peclet number, the Courant number, and maximum grid cell size changes for non-uniform grids. In addition, the user should assess the impacts of choice of advection solver, and refinements in the resolution of both the grid spacing and the transport time step size on the solution to ensure that the model setup is satisfactory. Increased resolution is not warranted at the point where there is negligible change in the results. The potential for numerical-solution related errors should be discussed when documenting a model and considered when interpreting the results.

The RT3D numerical code solves the reactive transport system described by Equation 1 using an operator-split strategy [Clement et al., 1998; Simpson et al., 2005] to uncouple the reaction terms from the advection, dispersion, and source/sink terms of the governing transport equations. These uncoupled components of the transport equation are treated as separate "packages" by RT3D in terms of the input files and the solution. In particular, the reaction terms $\left(r_{k}\right)$ in Equation 1 for all contaminant species can be assembled as a set of ordinary differential equations (ODEs) that describes the reaction rate and pathway details. Specific reaction kinetic expressions may be assembled in a reaction "module" that plugs into the reaction package for solution during the overall process. RT3D includes a variety of reaction modules for specific purposes, including those designed for evaluation of MNA as a remedy for chlorinated solvent 
contamination (Section 7.0). Additionally, the user may define a set of kinetic reaction expressions in a user-defined reaction module to account for processes not included in the standard reaction modules. The following sections examine the mathematical expressions of each component of the governing transport equation and discuss the type of information available to select parameter values for these expressions.

\subsection{Advection}

Groundwater flows primarily in response to pressure gradients. The basic relation of pressure gradients and groundwater flow is the Darcy equation. Equation 2 shows is a formulation of the Darcy equation that provides the groundwater flow velocities used by RT3D in solving the transport equation.

Equation 2 illustrates that the distribution of hydraulic conductivity is the key aquifer parameter that determines the rate of groundwater flow for a given hydraulic head gradient. The flow path of groundwater is via the path of least resistance, thus developing an adequate representation of the hydraulic conductivity distribution is a key issue in configuring the numerical model.

Sources of hydraulic conductivity values include literature information, laboratory tests, and field tests. Literature information provides estimates for the intrinsic hydraulic conductivity for specific sediment types [e.g., Freeze and Cherry, 1979]. This type of information can be useful to estimate the hydraulic conductivity distribution from geologic borehole log information. There are numerous methods available to interpolate geologic data from borehole logs into a distribution of subsurface geologic layering within a defined domain (e.g., kriging techniques). The hydraulic conductivity of a specific model grid cell can be estimated using a weighted average of the intrinsic hydraulic conductivity for different sediment types (e.g., sand, silt, and clay) based on the percentage of different sediment types interpolated to the specific grid cell. Data for the intrinsic hydraulic conductivity of specific sediment types can also be estimated using site-specific tests. Sediment samples of specific sediment types can be tested in the laboratory using standard techniques to determine the permeability [e.g., Klute and Dirksen, 1986]. These techniques provide a vertical hydraulic conductivity estimate for the sediment sample that can be used to interpret the intrinsic horizontal hydraulic conductivity for the sediment type of the sample. Hydraulic properties can also be related to sediment physical properties such as grain size distributions. Field tests in selected sediment layers can be conducted as well. Typical field tests include slug tests and pumping tests. Procedures, interpretation, and limitations of these tests are readily available [e.g., Kruseman and de Ridder, 1990]. The pumping test, in particular, can be applied to evaluate the hydraulic conductivity over a larger area and determine a conductivity value that is a composite of the intrinsic conductivities for the layers present within the test area. This composite may be of value if it is not practical to represent all of the individual subsurface layers within the numerical model grid. 
For the hydraulic conductivity in the vertical direction, the intrinsic conductivity approach described above can be used with values from literature, laboratory tests, or estimates based on horizontal conductivity values if the subsurface layering can be defined. If the subsurface can't be directly defined (e.g., for complex systems with layers too fine to resolve), an anisotropy factor can be used as a way to estimate the relative horizontal and vertical conductivity values. Typically transverse conductivity is assumed to be the same as the conductivity in the primary horizontal flow axis. Estimates for anisotropy are typically based on an assessment of the contrast of hydraulic conductivity between subsurface layers.

Other parameters are also important for calculating groundwater flow for some settings. For example with transient conditions, an estimate for the storage coefficient (confined aquifers) and specific yield (unconfined aquifers) is needed. Estimated values for these parameters can be obtained in the literature or from analysis of field tests. Additionally for advection velocity and transport calculations, an estimate for porosity is needed. Literature values for porosity are available based on sediment type. It is also possible to estimate porosity in the field using conservative tracer tests.

Advection can also be influenced by density differences induced by high concentrations of solutes in the groundwater [Russell et al., 1992; Barth et al., 2001; Wood et al., 2004; Simmons, 2005]. For typical MNA scenarios, density differences imposed by disperse dissolved contaminant concentrations are not significant. However, density issues should be considered for sites that include high concentration source areas where density driven flow may have impacted the distribution of the downgradient plume or where there are natural interfaces between higher and lower density groundwater within the modelled area (e.g., for coastal areas [e.g., Smith and Turner, 2001; Westbrook et al., 2005]). Density-driven advection is not currently supported by RT3D. Advection in fractured systems is also not currently supported by RT3D.

\subsection{Dispersion}

Dispersion is comprised of molecular diffusion and velocity-related mechanical dispersion. In numerical modelling, dispersion is quantified using the dispersion coefficient and related tensor components representing the dispersion along the different directions. Dispersion is not readily measurable in the field and is generally viewed as a term that combines the effects of pore-scale processes and of spatial variation in hydraulic conductivity. Based on the scale of the plume, an initial estimate of an appropriate longitudinal dispersivity value can be obtained from tabulated data [e.g., Gelhar et al., 1992] or published correlations [e.g., Ayra, 1986; Pickens and Grisak, 1981; Neuman, 1990; Xu and Eckstein, 1995 and 1997; Perfect et al. 2002]. Dispersivity in the directions transverse and vertical to the plume axis is generally lower than that in the longitudinal direction. Less data is available on transverse and vertical dispersivity; that which is available is mostly of low reliability [Gelhar et al., 1992]. Rule-of-thumb type estimates are often used for transverse dispersivity (equal to $10 \%$ of longitudinal dispersivity) and vertical 
dispersivity (equal to $1 \%$ of longitudinal dispersivity). The use of tabulated data and correlations based on such data has several drawbacks. First, site-specific heterogeneity is a major influence on the dispersivity, and the tabulated data is likely not specific to the site of interest. Secondly, an examination of the tabulated data will reveal that, for a give plume scale, the dispersivity can range over an order of magnitude or more.

The character of the plume concentration profiles can also provide qualitative information to assess appropriate dispersion values. For instance, plumes with sharper concentration fronts would tend to indicate lower dispersion coefficient values.

Regardless of the source of estimates, the dispersion coefficient values need to be examined as part of the calibration process. Note that the apparent dispersion may not be entirely from dispersion processes, most notably in cases where there are transient flow effects. Neglecting transience can lead to the use of "apparent transverse dispersivities" that are larger than the actual transverse dispersivity [Johnson and Spencer, 2003].

\subsection{Adsorption}

The most common assumption for groundwater modelling is that sorption is solely comprised of equilibrium adsorption processes (i.e., the sorption/desorption occurs much faster than the transport time scale). The most common equilibrium adsorption assumption is a linear partitioning isotherm, for which a single coefficient can be used to describe the sorption processes. This linear equilibrium partitioning coefficient, $\mathrm{K}_{d}\left(\mathrm{~L}^{3} / \mathrm{M}\right)$, is defined as the ratio of the concentration of the species in the aqueous phase to the concentration of the species in the sorbed phase (Equation 4).

$$
\hat{C}_{k}=K_{d, k} \cdot C_{k}
$$

Applying the chain rule of calculus, the second term on the left hand side of Equation 1 can be expanded to

$$
\frac{\partial \hat{C}_{k}}{\partial t}=\frac{d \hat{C}_{k}}{d C_{k}} \frac{\partial C_{k}}{\partial t}
$$

If we define a retardation factor, $\mathrm{R}_{\mathrm{k}}$ (dimensionless), for the $\mathrm{k}^{\text {th }}$ species as shown in Equation 6, then take the derivative of Equation 4, Equations 4, 5, and 1 can be combined into Equation 7.

$$
R_{k}=1+\frac{\rho_{b} K_{d, k}}{\theta}
$$




$$
R_{k} \frac{\partial C_{k}}{\partial t}=\frac{\partial}{\partial x_{i}}\left(D_{i j} \frac{\partial C_{k}}{\partial x_{j}}\right)-\frac{\partial\left(v_{i} C_{k}\right)}{\partial x_{i}}+\frac{q_{s}}{\theta} C_{s, k}+\frac{1}{\theta} \sum r_{k}
$$

The value of $\mathrm{K}_{\mathrm{d}}$ for a chemical species can be estimated based on its relationship to other laboratory-measured parameters or through laboratory experiments. Within an aquifer, $\mathrm{K}_{\mathrm{d}}$ values have a spatial distribution dependent on the distribution of the sediment properties that impact the partitioning process. In practice, the detail of this distribution is not known and sorption is quantified by a single coefficient over a large-scale.

In high-carbon soils, it has been demonstrated that the amount of nonionic organic chemicals sorbed varies from soil to soil and that such variations are primarily caused by the organic content of the soil [Jeng et al., 1992; Lyman et al., 1990; Bishop et al., 1989]. However, mineral-driven sorption becomes important as organic carbon content diminishes to below $0.1 \%$ [Kile et al., 1995]. At levels of organic carbon above $0.1 \%$, the normalized sorption coefficient $\left(\mathrm{K}_{\mathrm{oc}}\right)$ represents an important parameter that can be used to estimate the soil/water equilibrium partition coefficient $\left(\mathrm{K}_{\mathrm{d}}\right)$ with this equation:

$$
K_{d}=f_{o c} \cdot K_{o c}
$$

where $f_{o c}$ is the mass fraction of organic carbon (mass-oc/mass-soil) in the soil and $K_{d}$ is the soil/water equilibrium partition coefficient $[(\mathrm{mg} / \mathrm{kg}$-soil $) /(\mathrm{mg} / \mathrm{L})]$. It is important to note that at levels of organic carbon below approximately $0.1 \%$, this relationship will likely underestimate $\mathrm{K}_{\mathrm{d}}$ because it neglects mineral-driven sorption. In those cases, the real quantity of attached material will be higher than those predicted by Equation 8 .

Many researchers have developed methods for estimating $\mathrm{K}_{\mathrm{oc}}$ based on measurable properties such as the octanol/water partition coefficient $\left(\mathrm{K}_{\mathrm{ow}}\right)$. Two common correlations are given in the following equations [Lyman et al., 1990; Bishop et al., 1989]:

$$
\begin{aligned}
& \log \left(K_{o c}\right)=3.64-0.55 \cdot \log (S) \\
& \log \left(K_{o c}\right)=4.277-0.557 \cdot \log \left(S_{m}\right)
\end{aligned}
$$

where $\mathrm{S}$ is the water solubility of the organic compound $(\mathrm{mg} / \mathrm{L})$, and $\mathrm{S}_{\mathrm{m}}$ is the molar water solubility of the organic compound $(\mu \mathrm{mol} / \mathrm{L})$.

Non-linear equilibrium relationships can also be described numerically in RT3D using data from laboratory experiments and a concentration-dependent mathematical description of a sorption/desorption isotherm (e.g., the Freundlich or Langmuir isotherms). These non-linear 
equilibrium relationships may be more appropriate than a linear relationship in some aquifers [e.g., Pedit and Miller, 1994]. Karickhoff et al. [1979] suggest that non-linear relationships may be needed when contaminant concentrations are more than one half the aqueous-phase solubility of the compound or $10^{-5} \mathrm{M}$ whichever is lower.

It is also possible to configure RT3D to account for non-equilibrium sorption processes. The built-in "Rate-Limited Sorption" RT3D reaction module provides an example of kinetically controlled adsorption for a single species (with no other chemical reaction). Using the typical chemical engineering approach taken by Haggerty and Gorelick [1994], the adsorption/desorption is described based on a concentration driving force and a mass transfer coefficient. The mobile and adsorbed fractions are treated as separate species, the latter of which does not undergo transport. Equations 11 and 12 describe the sorption kinetics for the mobile and immobile fractions, respectively.

$$
\begin{aligned}
& \frac{d C_{\text {mobile }}}{d t}=-\alpha\left(C_{\text {mobile }}-\frac{C_{\text {sorbed }}}{\lambda}\right) \\
& \frac{d C_{\text {sorbed }}}{d t}=\frac{\alpha \theta}{\rho_{b}}\left(C_{\text {mobile }}-\frac{C_{\text {sorbed }}}{\lambda}\right)
\end{aligned}
$$

In Equations 11 and 12, $\alpha$ is a first-order mass-transfer rate coefficient $(1 / \mathrm{T}), \lambda$ is a linear partitioning coefficient (i.e., $\left.\mathrm{K}_{\mathrm{d}}\right)\left(\mathrm{L}^{3} / \mathrm{M}\right)$, and the $\mathrm{C}_{\text {mobile }}$ and $\mathrm{C}_{\text {sorbed }}$ are the species concentrations (in $\mathrm{M} / \mathrm{L}^{3}$ and $\mathrm{M} / \mathrm{M}$, respectively). To use this non-equilibrium adsorption process, the equilibrium $\mathrm{K}_{\mathrm{d}}$ values for both species must be set to zero. The value for $\lambda$ is set as a separate parameter. As with the linear equilibrium partitioning approach, the mass transfer process has a spatial distribution dependent on the distribution of the sediment properties that impact the partitioning process. Laboratory experiments are the primary data sources for estimating the coefficients of the mass transfer approach. Presence of an irreversible sorption capacity for the aquifer can be implemented numerically as a contaminant sink.

A kinetically controlled desorption rate can provide an explanation for contaminant rebound or plume tailing effects that are sometimes observed. Several types of numerical formulations for the mass transfer relationship have been presented in the literature. One example is a twocomponent system combining equilibrium and kinetically controlled sorption [e.g., Brusseau and Rao, 1989]. Kinetically controlled sorption can also be modelled using a Fick's Law approach with various assumptions related to the type of diffusional regime [e.g., Farrell et al., 1999; Farrell and Reinhard, 1994; Rugner et al., 1999; Carroll et al., 1994; Werth et al., 2000]. Alternatives to these basic approaches include dual-equilibrium models [e.g., Chen et al., 2001] or multiple mass transfer rate models [e.g., Culver et al., 1997]. 


\subsection{Source/Sinks}

There are several types of sources and sinks that can be relevant for reactive transport modelling. This section provides a brief description of NAPL dissolution (constant concentration, decaying concentration, kinetic dissolution), volatilization, groundwater influx/outflux, and phytoremediation effects.

\subsubsection{NAPL-Water Mass Transfer}

Quantification of a NAPL dissolution rate may be a key component for modelling some plumes with persistent source areas. There are three primary methods for modelling the interaction of NAPL and aqueous-phase contaminant concentrations.

Constant Concentration - In some cases it may be appropriate to use a boundary condition of a constant concentration in model grid cells corresponding to the location of the DNAPL source. The concentration of species for this cell can be estimated based on the effective solubility for the each species [Cohen and Mercer, 1993]. In many cases, field data indicate that the dissolvedphase concentration of DNAPL components is significantly lower than what would be predicted by the effective solubility. In these cases, the constant concentration value can be set equal to the field-observed value if the source is expected to remain for a long period of time relative to the time for transport of the plume toward the receptors.

Decaying Concentration - Dissolution of NAPL over time or application of source remediation may decrease the concentration of contaminants in the source area. As an approximation, a firstorder decay in the concentration of the NAPL components (which may each decay at a different rate) in the source cells can be implemented.

Kinetic Dissolution - A kinetic expression for the DNAPL component dissolution rate can be included in the model if sufficient information is available to estimate the parameters. Similar to non-equilibrium adsorption, a mass transfer approach is used for kinetic NAPL dissolution. A driving force for the mass transfer is developed based on concentrations that can be calculated and tracked within the model. Equations 13 and 14 are an example of how non-equilibrium NAPL dissolution can be represented.

$$
\begin{aligned}
& \frac{d C_{\text {mobile }}}{d t}=\gamma\left(C_{N A P L}^{\prime}-C_{\text {mobile }}\right) \\
& \frac{d C_{N A P L}}{d t}=-\frac{\gamma \theta}{\rho_{b}}\left(C_{N A P L}^{\prime}-C_{\text {mobile }}\right)
\end{aligned}
$$

In these equations, $\mathrm{C}_{\text {mobile }}$ is the aqueous-phase concentration of the NAPL species $\left(\mathrm{M} / \mathrm{L}^{3}\right), \mathrm{C}_{\mathrm{NAPL}}$ is the mass of NAPL-phase per unit aqueous volume $\left(\mathrm{M} / \mathrm{L}^{3}\right), \mathrm{C}_{\mathrm{NAPL}}^{\prime}$ is the solubility of the NAPL 
species, and $\gamma$ is a mass transfer coefficient (1/T). Additional information about DNAPL dissolution mechanisms is available in the literature [e.g., Clement et al., 2004a and 2004b; Miller et al., 1990 and 1998; Powers et al., 1991 and 1994].

\subsubsection{Volatilization}

There are three mass transfer processes that must be quantified to estimate the overall transfer of chlorinated solvents from the groundwater to the gas phase in the vadose zone. Figure 1 illustrates the concept applied for mass transfer at the groundwater table interface. At this interface, there is a mass transfer resistance associated with chlorinated solvent molecules crossing the interface. On either side of this interface, there are diffusion layers (gas film and liquid film) that affect the rate at which the chlorinated solvent can reach the groundwater table interface from the bulk groundwater and the rate at which the chlorinated solvent can move away from the interface into the bulk vadose zone gas phase. The estimate of overall mass transfer rate is a function of the parameters that control these three mass transfer processes.

The parameter controlling mass transfer at the groundwater table interface is the Henry's Law equilibrium partitioning coefficient. The Henry's Law coefficient is expressed as the concentration of a species in the vapor phase divided by the concentration of the species in the aqueous phase when these two phases are in equilibrium with respect to the species of interest. Chlorinated solvents have a relatively high Henry's Law coefficient; consequently, they can readily partition into the vapor phase across the groundwater table interface.

The diffusion processes to and away from the groundwater table interface are controlled by the diffusion coefficient in the medium (water or air) and the thickness of the diffusion layer. The diffusion coefficients for chlorinated solvents are on the order of $1 \times 10^{-6} \mathrm{~cm}^{2} / \mathrm{s}$ and $1 \times 10^{-2}$ $\mathrm{cm}^{2} / \mathrm{s}$ in water and air, respectively [Lyman et al., 1990]. The thickness of the diffusion layer is dependent on the hydraulic regime and physical nature of the liquid-gas system. The diffusion 


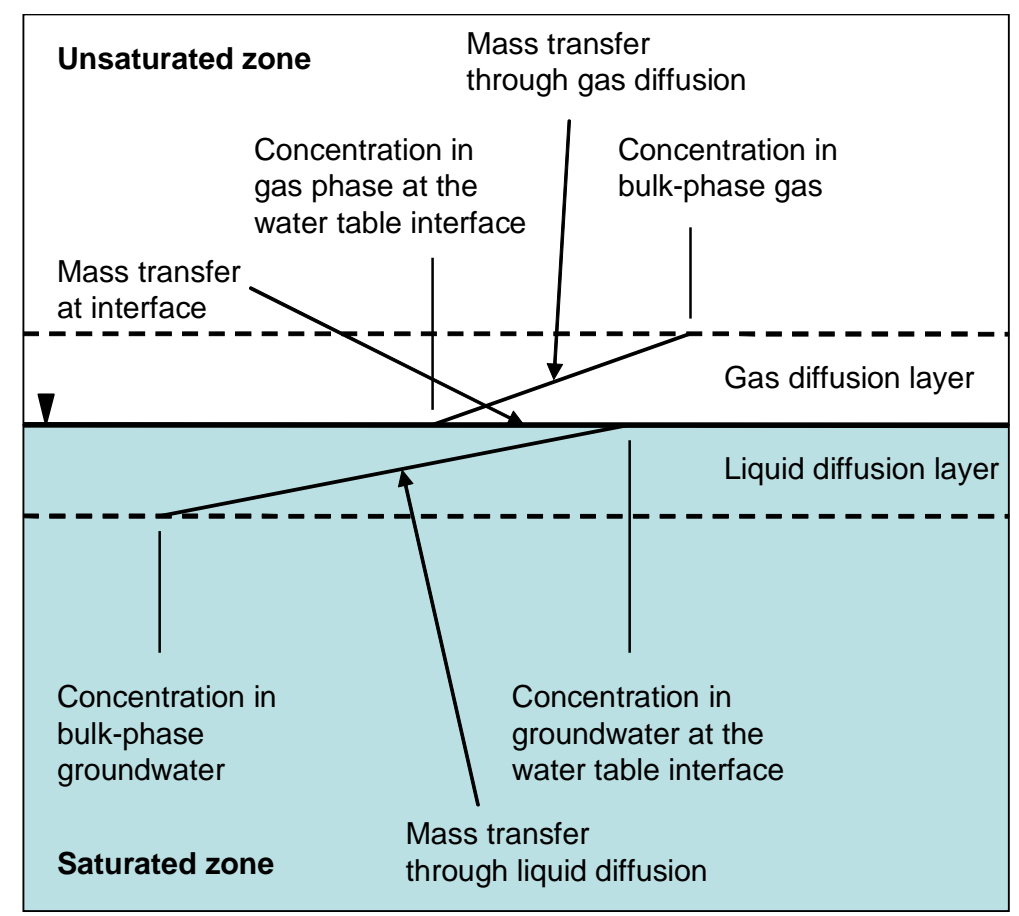

Figure 1. Mass Transfer Concept at the Groundwater Table Interface

layer thickness in the gas phase and groundwater must be estimated for the given site conditions. The mass transfer rate is significantly influenced by the diffusion layer thickness in the groundwater and minimally influenced by the diffusion layer thickness in the gas phase.

Using the above mechanisms, the mass transfer rate at the groundwater table as a function of bulk groundwater concentration can be estimated. Being a single (aqueous) phase code, RT3D does not have a built in method for describing volatilization. However, the mass transfer due to volatilization could be represented in a user-defined reaction module where model grid cells at the water table have an additional loss term. The volatilization loss term could use a lumped mass transfer coefficient similar to the approach for non-equilibrium NAPL dissolution or could use a resistance-in-series approach with individual mass transfer coefficients for the zones described above.

\subsubsection{Groundwater Influx/Outflux}

Introduction or removal of contaminants from the groundwater system can be an important factor in assessing the mass balance of the contaminant plume, depending on the specific site. Natural (e.g., recharge, evapotranspiration, rivers, drains) and introduced (extraction and injection wells) can be specified in MODFLOW/RT3D as sources/sinks for groundwater flow and thus for contaminant mass carried with the groundwater. Extraction and injection wells may be important as part of modelling, for instance, EA/MNA combinations. 


\subsubsection{Phytoremediation Effects}

There are three primary functions of phytoremediation that may need to be incorporated into modelling analysis. First, in some phytoremediation applications, plants can uptake and remove a significant amount of groundwater from the aquifer. This hydraulic impact on the aquifer can be applied as a water sink (e.g., a well) within the modelled domain or through evapotranspiration. Information about the rate of removal or the resultant cone of depression around the plants is needed to establish the parameters for this water sink. Second, phytoremediation may directly remove contaminant from the aquifer (e.g., through uptake and subsequent transpiration or in-plant degradation of the contamination). This contaminant impact can be incorporated with the hydraulic impact as part of the water sink. Lastly, phytoremediation may enhance or change existing degradation processes within a defined portion of the aquifer. These impacts on degradation processes may be the result of synergistic effects between the plant roots and the microbial population or perhaps caused by changing redox conditions. These degradation processes can be implemented in the same way that other spatial variations in reaction processes are included in the model configuration (Section 5.5 below). Information about the specific reactions and rates that occur in the phytoremediation zone are needed to select the appropriate rate expressions and coefficients for the model.

\subsection{Biological and Chemical Reactions}

The final term of the governing transport equation is the reaction component. The RT3D reaction module is used to encapsulate the factors that comprise the reaction term of the governing transport equation, including non-equilibrium mass transfer (e.g., adsorption, NAPL dissolution) and biological and chemical reactions. This section discusses the basis for modelling biological dechlorination reactions, while Section 6.0 describes the biological and abiotic dechlorination reactions that may occur for chlorinated ethenes, ethanes, and methanes.

Biological and chemical reaction processes can be described mechanistically or with general empirical relationships. For numerical groundwater modelling, empirical relationships providing an estimate of the overall rate of transformation and dependence of this rate on the concentrations of chemical species related to the transformation reaction are typically used. Contaminant transformation processes under natural attenuation conditions are typically described using a lumped first-order kinetic form (e.g., Equation 15) that has been effective in simulating transformation rates under a variety of conditions [U.S. EPA, 1998; Clement et al., 2000] (but see Johnson and Truex [2006] for discussion on the suitability of first-order expressions). It is also feasible to add dependencies of this rate related to the concentration of reactants or inhibitors. Common forms for reaction dependencies, such as for oxidation/ reduction state or specific reactant concentration, include inhibition terms and Monod-type terms as shown by Equations 16 and 17, respectively. 


$$
\begin{aligned}
& \frac{d C_{k}}{d t}=-k_{f w d} \cdot C_{k} \\
& \frac{d C_{k}}{d t}=\left(\frac{-k_{f w d} \cdot C_{k}}{K_{C} \cdot\left(1+\frac{C_{\text {inhibitor }}}{K_{i}}\right)+C_{k}}\right) \\
& \frac{d C_{k}}{d t}=\left(\frac{-k_{f w d} \cdot C_{k}}{K_{C}+C_{k}}\right)
\end{aligned}
$$

In Equations 16 and $17, \mathrm{k}_{\mathrm{fwd}}$ is the first-order rate coefficient for the $\mathrm{k}^{\text {th }}$ species $(1 / \mathrm{T}), \mathrm{K}_{\mathrm{C}}$ is the half saturation coefficient $\left(\mathrm{M} / \mathrm{L}^{3}\right), \mathrm{C}_{\text {inhibitor }}$ is the concentration of an inhibitor species $\left(\mathrm{M} / \mathrm{L}^{3}\right)$, and $\mathrm{K}_{\mathrm{I}}$ is an inhibition coefficient $\left(\mathrm{M} / \mathrm{L}^{3}\right)$.

While there are other factors that can impact dechlorination activity of bacteria, dechlorination reaction pathways and rates have been shown to vary as a function of the electron acceptor conditions. Hence, the electron acceptors and other geochemical indicators (e.g., redox potential, methane, total organic carbon, etc.) usually categorize the overall activity of bacteria at the site. In general, the sequence of electron acceptors (non-contaminant) from more oxidizing to more reducing conditions are: oxygen, nitrate, iron/manganese, sulfate, and carbon dioxide (methane production).

Section 6.0 discusses the dechlorination reactions as a function of three basic geochemical settings at a site: Aerobic, Anoxic, and Anaerobic. In most cases, the geochemical data available at a site is sufficient to identify which of these three settings describes the site or to divide the site into several segments with different geochemical settings (e.g., an anaerobic portion near the source and an aerobic portion at some point downgradient of the source). Using this type of information, RT3D can be configured to model these different redox zones reactions and rates specific to the geochemical setting in each zone [e.g., Johnson et al., 2003]. Alternatively, if a significant amount of temporal and spatial data are available/collected at a site, the oxidation/reduction conditions at any given point in the model can be explicitly modelled and RT3D can use this information to model the dechlorination reactions as a function of these conditions within each model grid cell. These two approaches are discussed further in Section 8.2.2.

In some cases, it may useful to describe both the substrate and the electron acceptor reactions and the correlation of these reactions to dechlorination rates. Expressions for these reactions can be developed based on knowledge of the metabolic respiration processes that have been 
examined in the literature or laboratory. This approach requires an in-depth knowledge of the metabolic processes at a site and adds additional parameters for which estimates are required. However, the basic approach of describing the correlation between substrate and electron acceptor reactions and dechlorination rate can be constructed and implemented with appropriate assumptions about the dependency of the dechlorination rate on the concentration of other species (e.g., electron acceptors) in the groundwater, thus simplifying the expressions. A key limitation of this approach for natural attenuation modelling is that the substrate type and flux is not well defined under natural attenuation conditions. Thus, assumptions about the metabolic reactions are typically necessary. More typically, kinetic expressions incorporating substrate and electron acceptor reactions and the correlation of these reactions to dechlorination rates are applied for accelerated bioremediation applications where there is much better information about the type and flux of the substrate.

Sources of information on reaction processes and rate coefficients relevant to numerical modelling include laboratory studies, literature information, and in some cases, field data. Laboratory microcosm tests provide data on the type of reactions and rate of reactions that occur in a sediment sample under the conditions of the microcosm experiment. It is not possible to duplicate the exact conditions in the field within the microcosm test. Additionally, the sediment for the test has been disturbed and taken out of its context with surrounding sediment. However, if care is taken to maintain conditions in the microcosm that are similar to the conditions in the aquifer, the data can be useful to derive a description of relevant reaction processes for the area of the aquifer represented by the sediment and conditions of the microcosm test. The reaction rates determined in the microcosm test are typically higher than the reaction rates that can be expected in the field. However, the relative rates of different reaction processes (e.g, the rate of TCE transformation relative to the rate of DCE transformation) are likely to be consistent between the laboratory and the field. It is then necessary within model calibration to estimate the correction factor between the laboratory-derived rates and the rates in the field. It has typically been the practice to determine site-specific transformation rates, but there are rate data available in the literature that may provide useful information for comparison to the site-specific rates. It may also be reasonable in some cases to use reaction process and rate data from other similar sites as a starting point for developing the reaction processes at a site. Microbial characterization of the site may be of use to establish whether specific organisms, such as those of the dehalococcoides genus, are present as a guide for interpreting the probable reaction processes. 


\subsection{Description of Dechlorination Reactions}

The geochemical conditions at a site significantly impact the type of dechlorination reactions that will occur. At one end of the geochemical spectrum is the aerobic geochemical setting where oxygen is present as the primary electron acceptor for subsurface bacteria. Because oxygen is generally preferred by bacteria over all other electron acceptors and is toxic to many anaerobic bacteria, the presence of oxygen defines a very specific type of bacterial activity. Once oxygen concentration drops below about $10 \%$ of its solubility limit, the activity of aerobic bacteria and the toxic effect of oxygen are greatly diminished. When oxygen is absent and there is sufficient substrate for anaerobic bacteria to flourish, there are clear end products that serve as indicators of significant anaerobic activity. Depending on the type of anaerobic bacteria that are dominating the subsurface, methane, reduced iron, and/or sulfide will be present and the concentrations of more oxidized electron acceptors such as nitrate and sulfate will be low. Under these anaerobic conditions, it has been demonstrated that dechlorination reactions usually occur in conjunction with the anaerobic activity that produces the indicator compounds. The anoxic geochemical condition describes the type of conditions where oxygen is not present at high enough levels to inhibit the activity of other bacteria, but there are no, or limited, indicators of significant anaerobic bacterial activity. It is more difficult to determine the type of biological dechlorination reactions that are occurring at the site under anoxic conditions. However, biological dechlorination reactions may still be a significant attenuation mechanism. Typically under the anoxic geochemical setting, more detailed investigations are needed to fully quantify the rate and extent of biological dechlorination at the site.

Abiotic chemical reactions can either be water-phase reactions, or catalyzed by aquifer materials. Water-phase abiotic reactions are included as part of the reaction tables below. These reactions are usually not significantly impacted by the geochemical conditions, though the rate of reaction is a function of temperature and, in some cases, $\mathrm{pH}$. Catalyzed abiotic reactions are not included as a separate category below, but are considered as part of the reactions that are dependent on sediment components such as iron. These reactions are considered to be essentially coupled with the corresponding biological reactions that reduce/oxidize aquifer sediment component

Table 2 lists the chlorinated chemical species under consideration in this document by contaminant group along with their abbreviation and chemical formula. The types of biological and abiotic dechlorination reactions that can occur are described in Table 3. 
Table 2. Chlorinated Contaminant Species by Contaminant Type

\begin{tabular}{|c|c|c|c|c|}
\hline $\begin{array}{l}\text { Contaminant } \\
\text { Group }\end{array}$ & Abbreviation & $\begin{array}{l}\text { Chemical } \\
\text { Formula }\end{array}$ & Contaminant Name & Synonyms \\
\hline \multirow[t]{6}{*}{ Chloroethenes } & PCE & $\mathrm{CCl}_{2}=\mathrm{CCl}_{2}$ & Tetrachloroethene & $\begin{array}{l}\text { Tetrachloroethylene, } \\
\text { Perchloroethene }\end{array}$ \\
\hline & TCE & $\mathrm{CHCl}=\mathrm{CCl}_{2}$ & Trichloroethene & Trichloroethylene \\
\hline & 1,2-cis-DCE & $\mathrm{CHCl}=\mathrm{CHCl}$ & cis-1,2-Dichloroethene & $\begin{array}{l}\text { cis-1,2-Dichloroethylene, } \\
\text { cis-DCE, c-DCE }\end{array}$ \\
\hline & $\begin{array}{l}\text { 1,2-trans- } \\
\text { DCE }\end{array}$ & $\mathrm{CHCl}=\mathrm{CHCl}$ & trans-1,2 -Dichloroethene & $\begin{array}{l}\text { trans-1,2- } \\
\text { Dichloroethylene, } \\
\text { trans-DCE, t-DCE }\end{array}$ \\
\hline & 1,1-DCE & $\mathrm{CCl}_{2}=\mathrm{CH}_{2}$ & 1,1-Dichloroethene & $\begin{array}{l}\text { 1,1-Dichloroethylene, } \\
\text { Vinylidene Chloride }\end{array}$ \\
\hline & VC & $\mathrm{CH}_{2}=\mathrm{CHCl}$ & Chloroethene & $\begin{array}{l}\text { Vinyl Chloride, } \\
\text { Chloroethylene }\end{array}$ \\
\hline \multirow[t]{7}{*}{ Chloroethanes } & $1,1,2,2-\mathrm{TeCA}$ & $\mathrm{CHCl}_{2}-\mathrm{CHCl}_{2}$ & 1,1,2,2-Tetrachloroethane & - \\
\hline & 1,1,2-TCA & $\mathrm{CH}_{2} \mathrm{Cl}-\mathrm{CHCl}_{2}$ & 1,1,2-Trichloroethane & Vinyl Trichloride \\
\hline & $1,2-\mathrm{DCA}$ & $\mathrm{CH}_{2} \mathrm{Cl}-\mathrm{CH}_{2} \mathrm{Cl}$ & 1,2-Dichloroethane & Ethane Dichloride \\
\hline & 1,1,1,2-TeCA & $\mathrm{CHCl}-\mathrm{CCl}_{3}$ & 1,1,1,2-Tetrachloroethane & - \\
\hline & 1,1,1-TCA & $\mathrm{CH}_{3}-\mathrm{CCl}_{3}$ & 1,1,1-Trichloroethane & 一 \\
\hline & 1,1-DCA & $\mathrm{CH}_{3}-\mathrm{CHCl}_{2}$ & 1,1-Dichloroethane & - \\
\hline & $\mathrm{CA}$ & $\mathrm{CH}_{3}-\mathrm{CH}_{2} \mathrm{Cl}$ & Chloroethane & Ethyl Chloride \\
\hline \multirow[t]{4}{*}{$\begin{array}{l}\text { Chloro- } \\
\text { methanes }\end{array}$} & CT & $\mathrm{CCl}_{4}$ & Tetrachloromethane & Carbon Tetrachloride \\
\hline & CF & $\mathrm{CHCl}_{3}$ & Trichloromethane & Chloroform \\
\hline & $\mathrm{DCM}$ & $\mathrm{CH}_{2} \mathrm{Cl}_{2}$ & Dichloromethane & $\begin{array}{l}\text { Methylene Dichloride, } \\
\text { Methylene Chloride }\end{array}$ \\
\hline & $\mathrm{CM}$ & $\mathrm{CH}_{3} \mathrm{Cl}$ & Chloromethane & Methyl Chloride \\
\hline
\end{tabular}


Table 3. Descriptions of Biological and Abiotic Dechlorination Reactions

Reaction

\section{Abbreviation Description}

Dechlorination of a compound where the compound is

Aerobic Cometabolism $\quad$ ACM

fortuitously degraded by an enzyme used in cellular metabolism - typically a monooxygenase enzyme.

ADM

Use of the chlorinated compound as an electron donor for aerobic metabolism.

\begin{tabular}{|c|c|c|}
\hline Abiotic Hydrolysis & $\mathrm{AH}$ & $\begin{array}{l}\text { Homogeneous abiotic dechlorination - no specific } \\
\text { reaction for this classification. }\end{array}$ \\
\hline Anaerobic Cometabolism & ANCM & $\begin{array}{l}\text { Dechlorination of a compound where the compound is } \\
\text { fortuitously used as a surrogate electron acceptor, } \\
\text { though the cell does not gain energy by reduction of the } \\
\text { compound. For the reactions listed as ANCM, } \\
\text { denitrification is an example metabolic process that } \\
\text { supports this activity. }\end{array}$ \\
\hline $\begin{array}{l}\text { Anaerobic Direct } \\
\text { Metabolism }\end{array}$ & ANDM & $\begin{array}{l}\text { Use of the chlorinated compound as an electron donor } \\
\text { for anaerobic respiration - typically coupled to iron } \\
\text { reduction. }\end{array}$ \\
\hline Dichloroelimination (biotic) & DC & $\begin{array}{l}\text { Dechlorination of a compound where the compound is } \\
\text { used as an electron acceptor, the bacteria may or may } \\
\text { not gain energy by reduction of the compound. This } \\
\text { reaction removes two chloride atoms in an elimination } \\
\text { reaction. The more general term for this reaction is } \\
\text { dihaloelimination, but may also be referred to as vicinal } \\
\text { reduction. }\end{array}$ \\
\hline $\begin{array}{l}\text { Dehydrochlorination } \\
\text { (abiotic) }\end{array}$ & $\mathrm{DHC}$ & $\begin{array}{l}\text { This reaction removes one chloride atom and one proton } \\
\text { in an elimination reaction. This reaction is usually } \\
\text { referred to as abiotic, but studies indicate that the } \\
\text { reaction can be enhanced/catalyzed by bacteria and/or } \\
\text { minerals (e.g., clay). The more general term for this } \\
\text { reaction is dehydrohalogenation and is sometimes } \\
\text { referred to as dehydrodehalogenation. }\end{array}$ \\
\hline $\begin{array}{l}\text { Reductive Dechlorination } \\
\text { (biotic) }\end{array}$ & $\mathrm{RD}$ & $\begin{array}{l}\text { Dechlorination of a compound where the compound is } \\
\text { used as an electron acceptor, the bacteria may or may } \\
\text { not gain energy by reduction of the compound. This } \\
\text { reaction removes one chloride atom from the compound } \\
\text { and replaces it with a proton. This reaction is sometimes } \\
\text { referred to as hydrogenolysis. }\end{array}$ \\
\hline
\end{tabular}

Based on the characteristics of the geochemical settings, some dechlorination reactions are very likely to occur, some highly unlikely to occur, and some may occur depending on specific circumstances. Figures 2 through 13 (after Truex et al. [2006]) illustrate the dechlorination reactions that may occur at a site depending on the geochemical conditions and contaminants 
present. These figures depict the reactions most likely to occur at a site and can be used to assess what other reactions are possible, but may need more detailed information to quantify. Rates, in the form of the half-life in years at a temperature of $25^{\circ} \mathrm{C}$ and $\mathrm{pH}$ of 7 , are presented for waterphase abiotic reactions that always occur and are not significantly dependent on site conditions. Rates for the other biologically catalyzed reactions cannot be defined generically. Nomenclature for each reaction type is listed in Table 3. References for laboratory data describing each reaction (except those noted as "highly unlikely") are provided corresponding to the footnote numbers shown in the figures. The references are not intended to represent an exhaustive literature review, but provide examples of laboratory information that is available to describe the reactions. For the geochemical setting categorization, the anaerobic and aerobic settings are defined such that they represent conditions where it is highly likely that specific reactions are occurring. For some reactions, additional information is also needed under aerobic or anaerobic geochemical settings to determine whether the reaction is occurring at a site. The anoxic geochemical setting represents sites where the criteria used to define the general geochemical conditions are not sufficient to determine the specific reactions that are likely to occur. Thus, for anoxic geochemical settings, more detailed information is always needed to determine what reactions are occurring. Based on the nomenclature and description in Table 3, Table 4 describes the type of additional characterization information that is necessary to determine whether a reaction is occurring. 


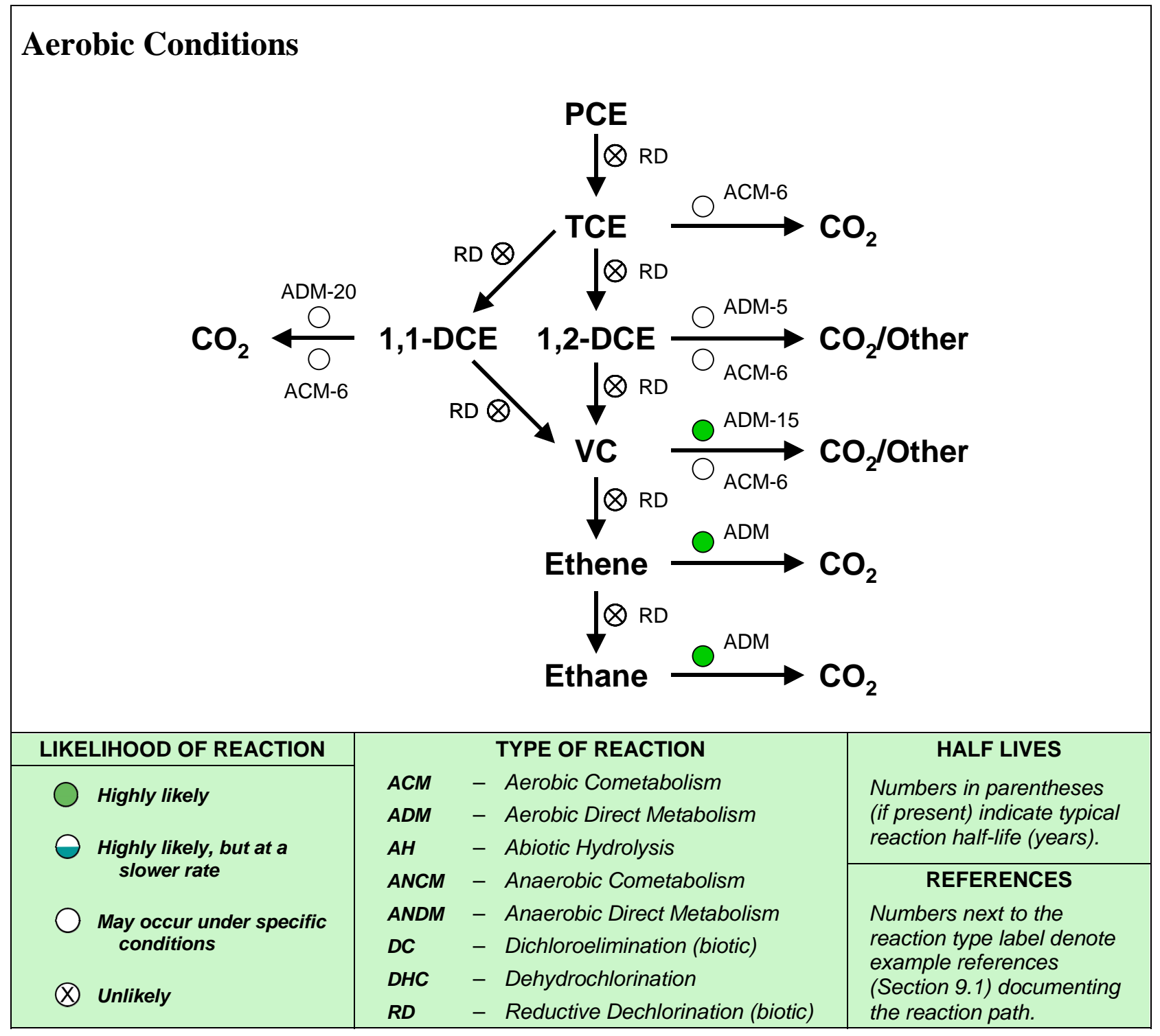

Figure 2. Dechlorination Reactions for PCE under the Aerobic Geochemical Setting 


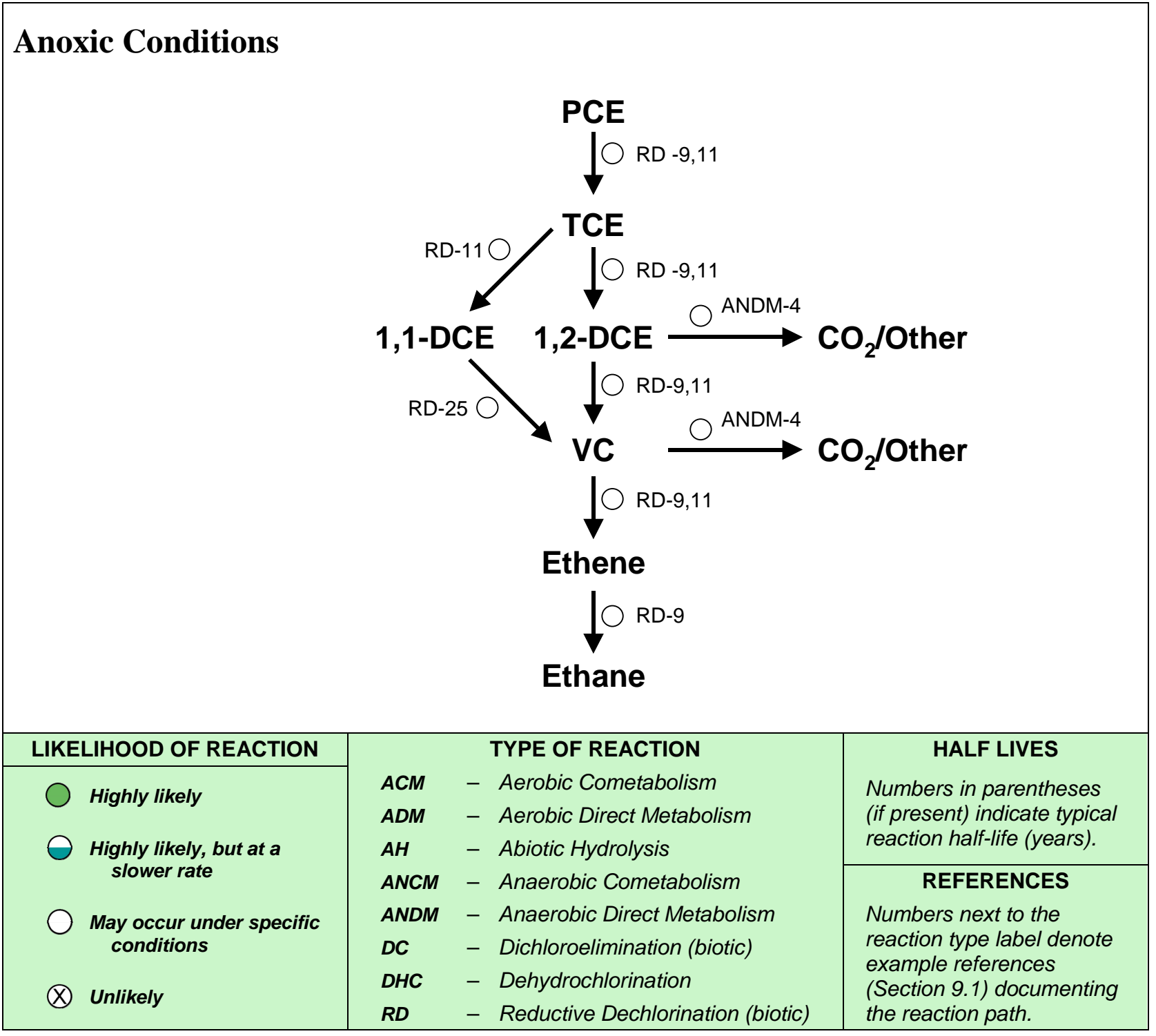

Figure 3. Dechlorination Reactions for PCE under the Anoxic Geochemical Setting 


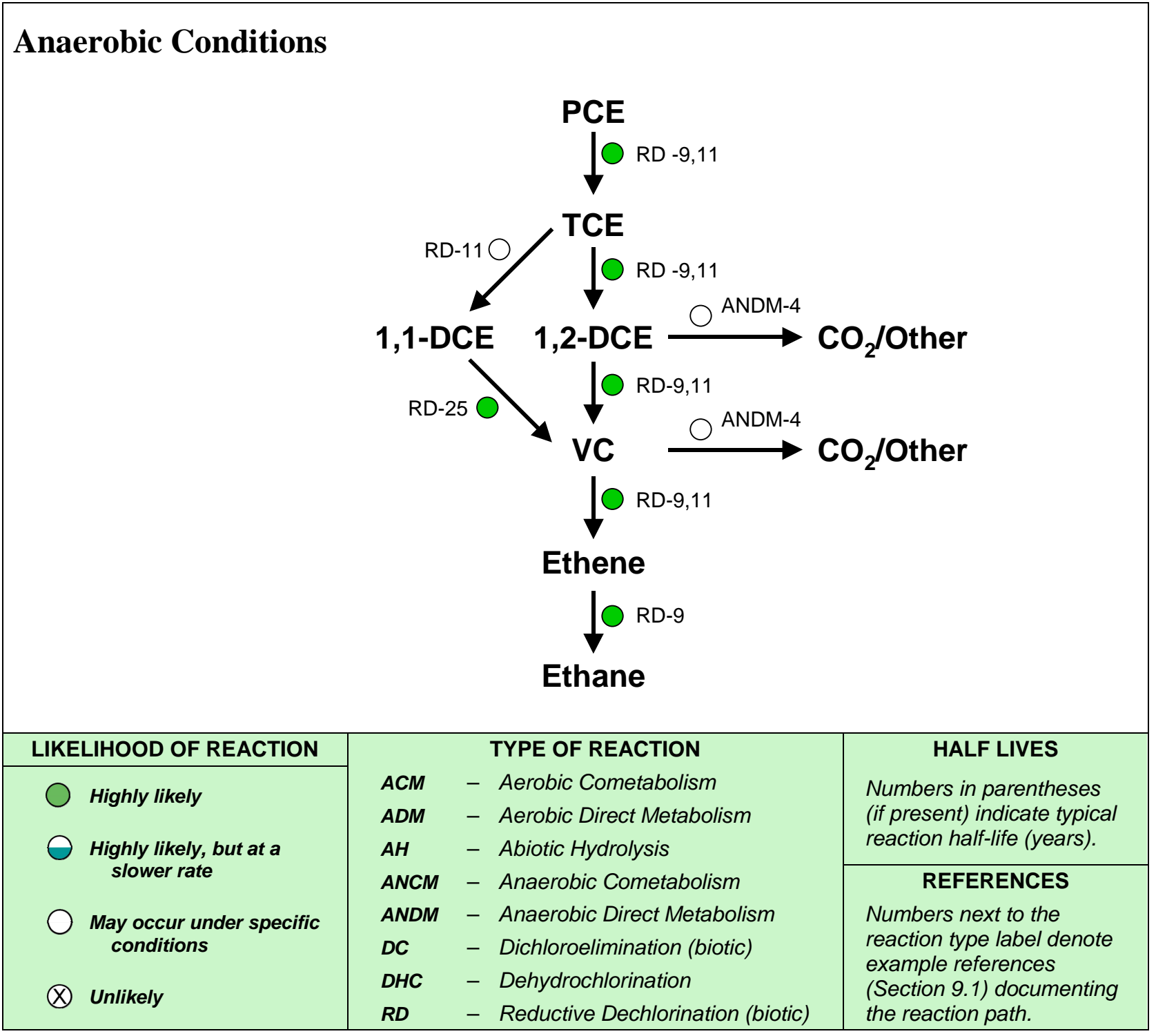

Figure 4. Dechlorination Reactions for PCE under the Anaerobic Geochemical Setting 


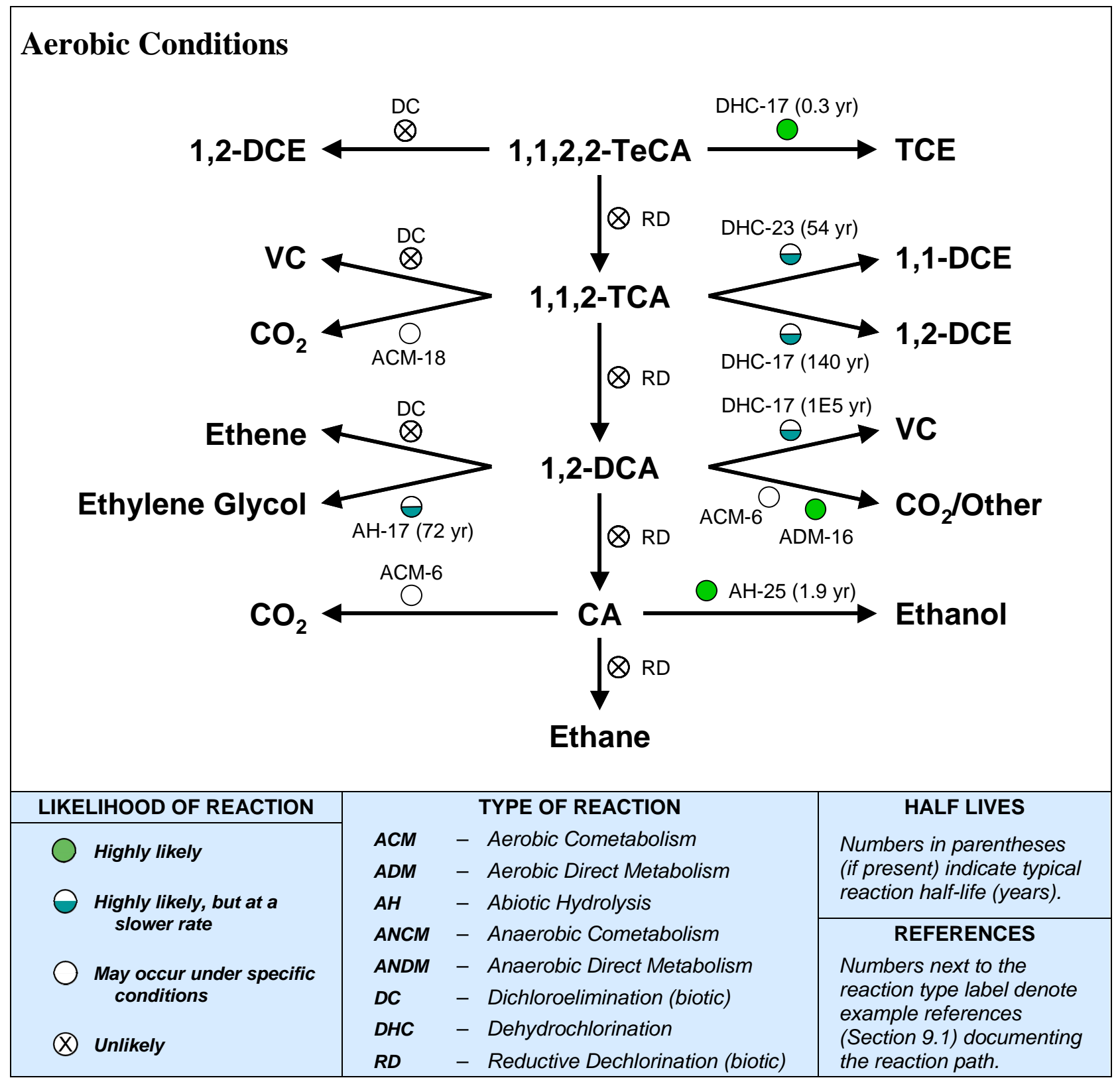

Figure 5. Dechlorination Reactions for 1,1,2,2-TeCA under the Aerobic Geochemical Setting 


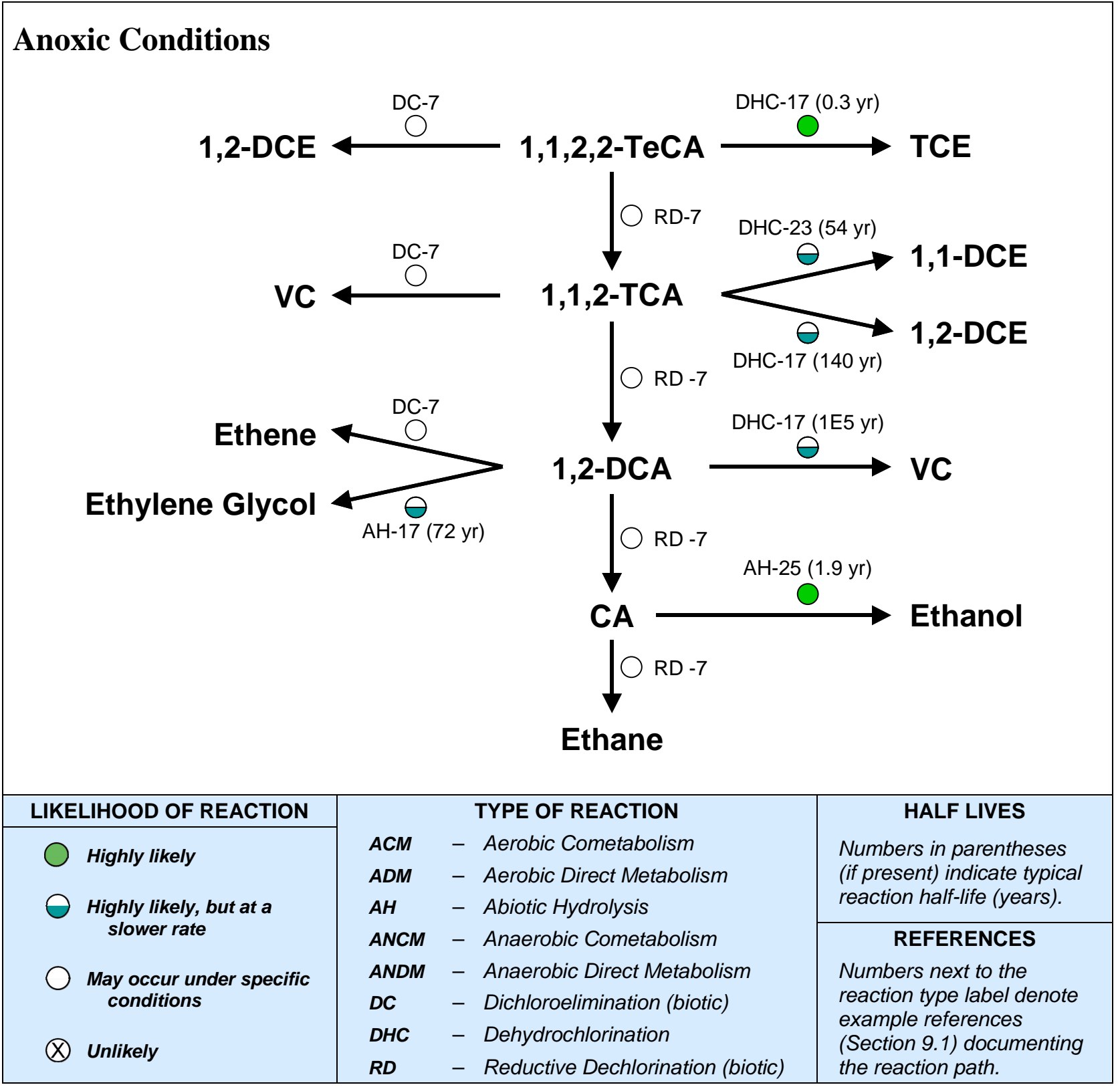

Figure 6. Dechlorination Reactions for 1,1,2,2-TeCA under the Anoxic Geochemical Setting 


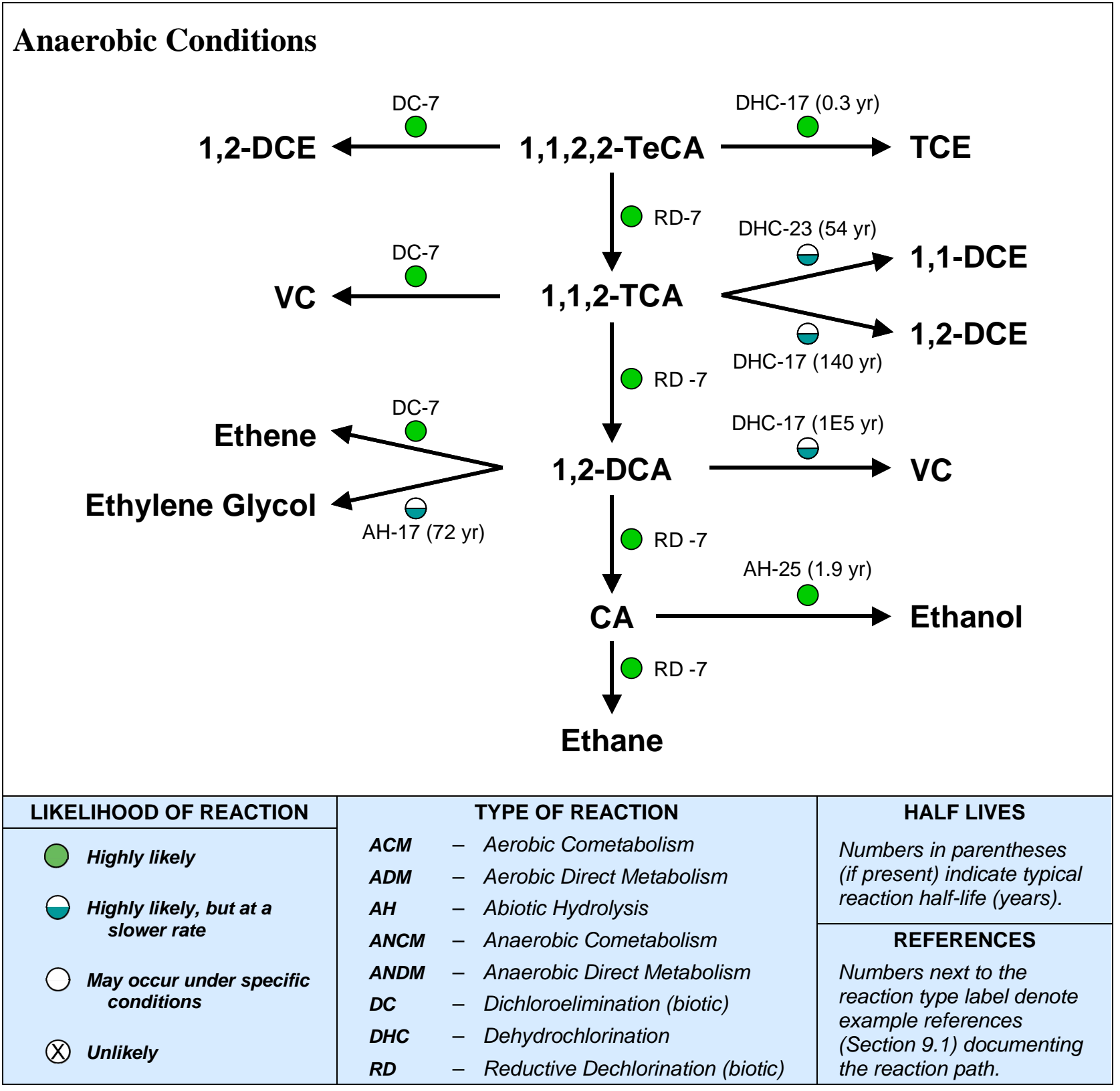

Figure 7. Dechlorination Reactions for 1,1,2,2-TeCA under the Anaerobic Geochemical Setting 


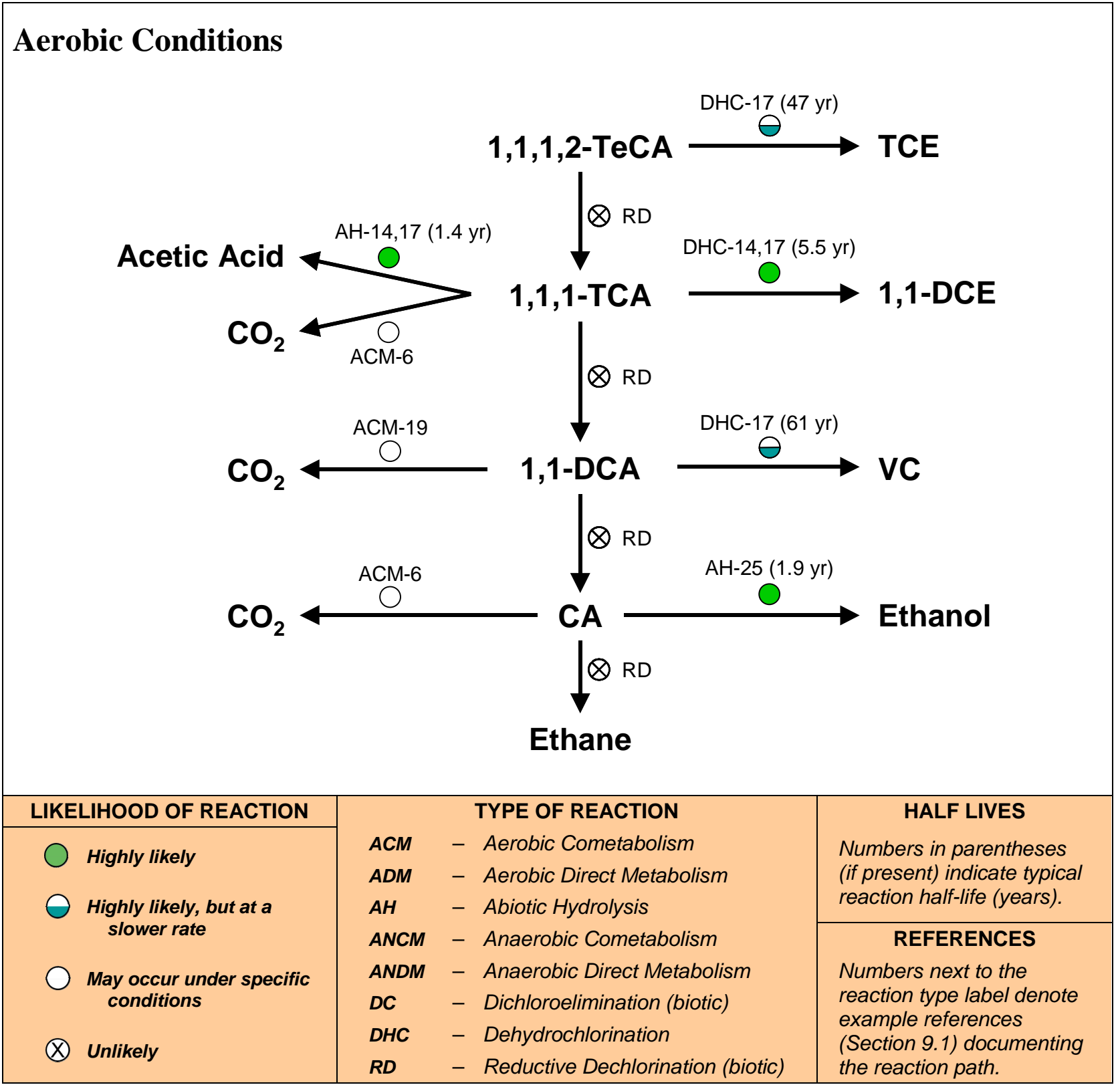

Figure 8. Dechlorination Reactions for 1,1,1,2-TeCA under the Aerobic Geochemical Setting 


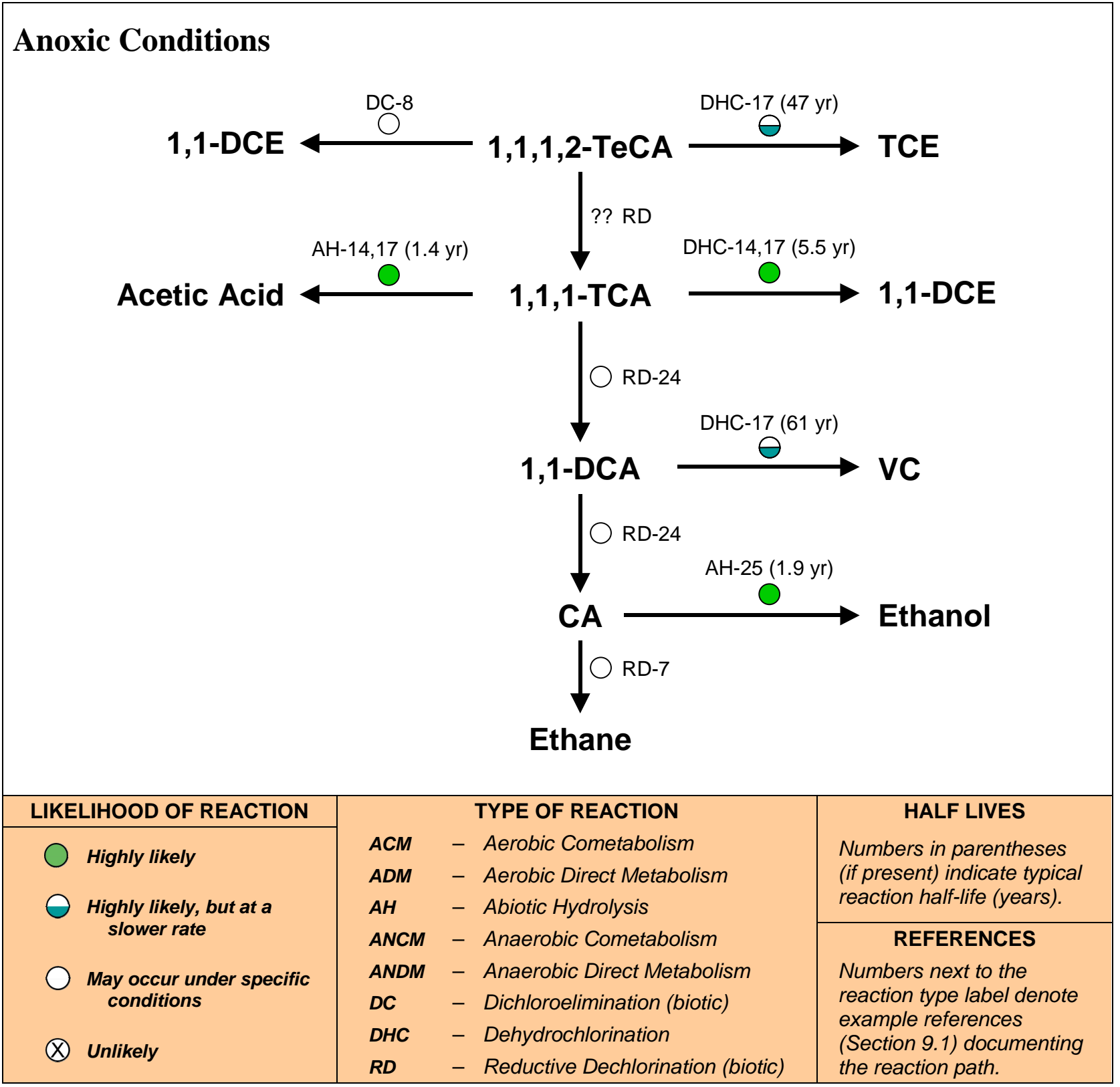

Figure 9. Dechlorination Reactions for 1,1,1,2-TeCA under the Anoxic Geochemical Setting 


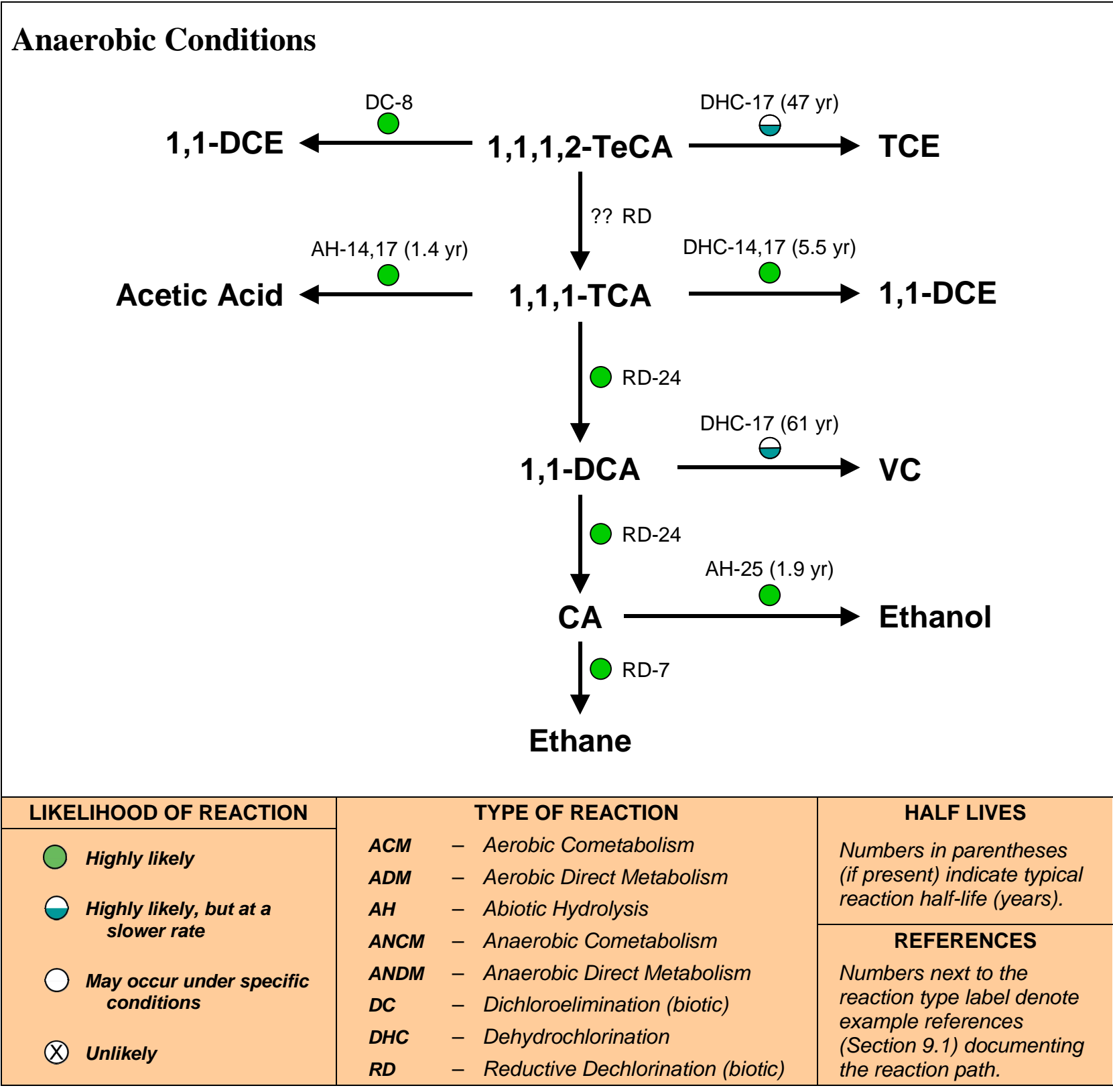

Figure 10. Dechlorination Reactions for 1,1,1,2-TeCA under the Anaerobic Geochemical Setting 


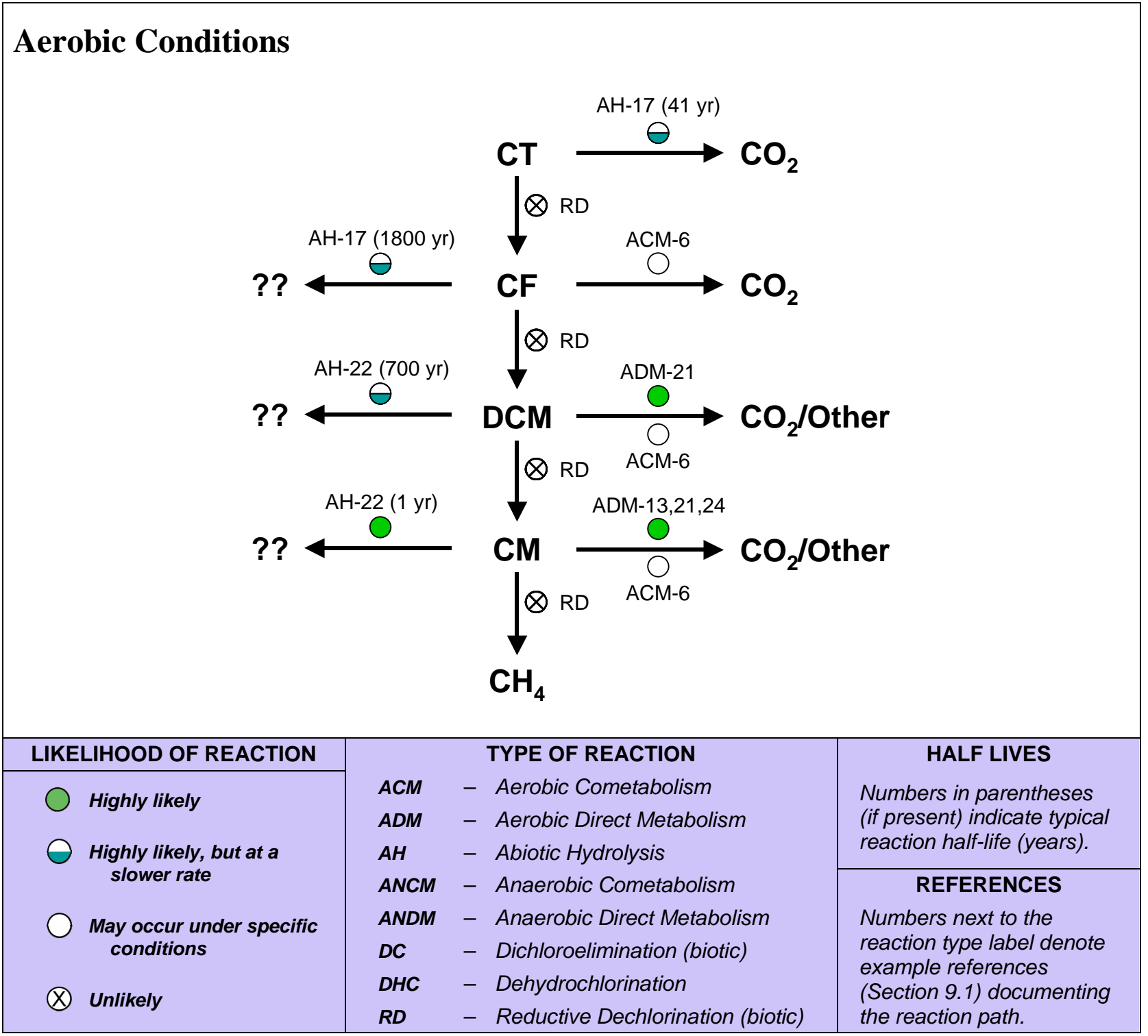

Figure 11. Dechlorination Reactions for CT under the Aerobic Geochemical Setting 


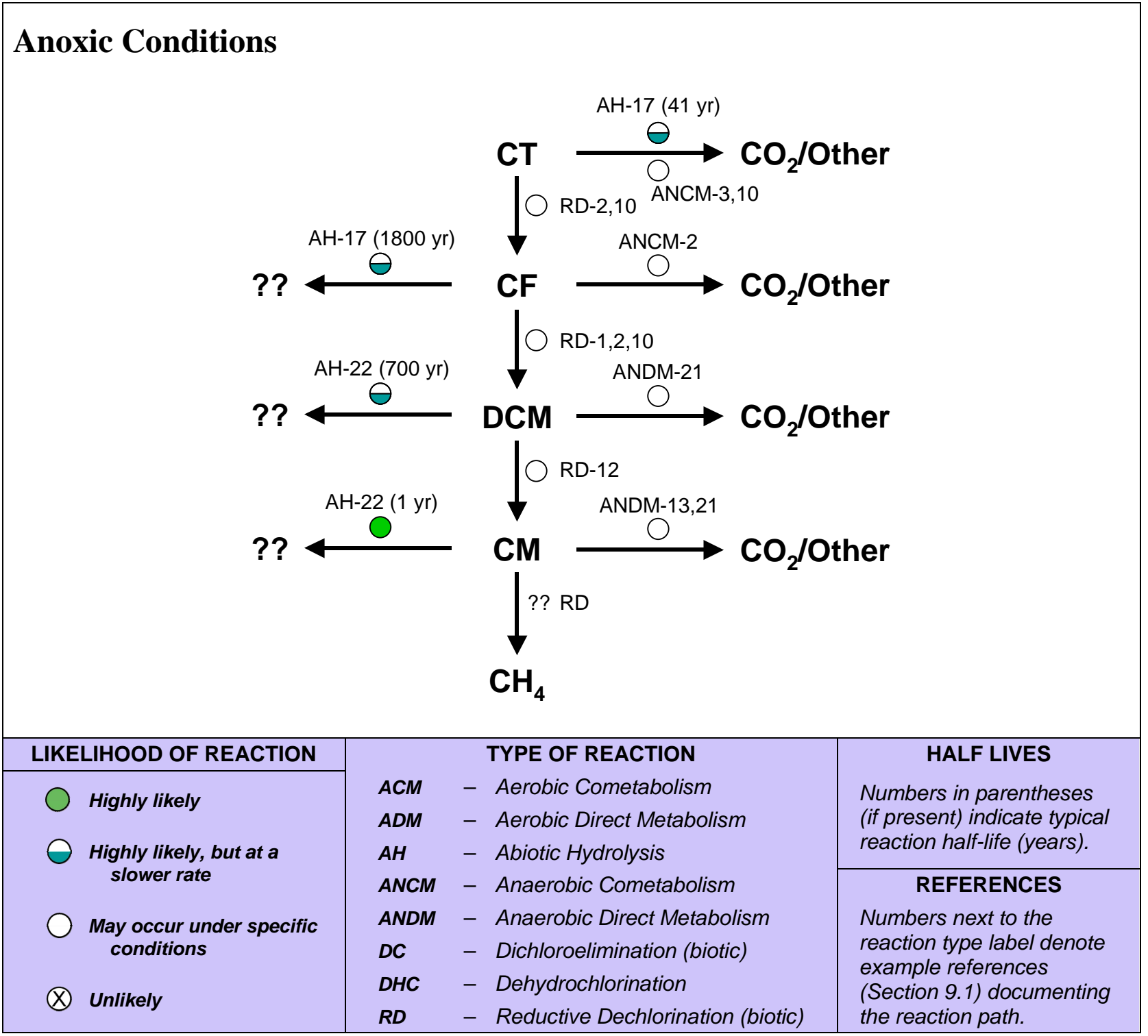

Figure 12. Dechlorination Reactions for CT under the Anoxic Geochemical Setting 


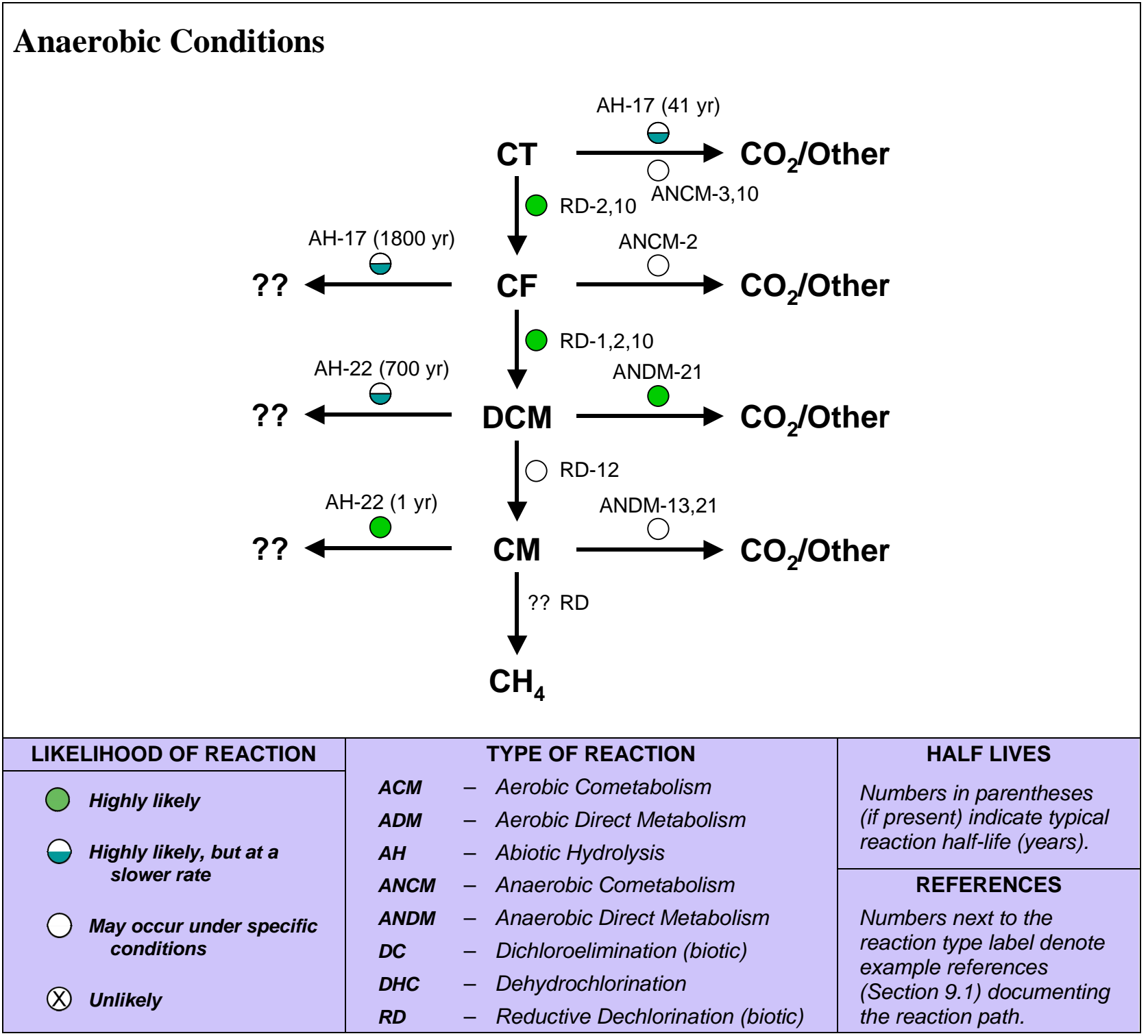

Figure 13. Dechlorination Reactions for CT under the Anaerobic Geochemical Setting 
Table 4. Additional Characterization Information to Assess Whether a Reaction Will Occur

\begin{tabular}{l|l|l|} 
Reaction & Abbreviation & Characterization Information
\end{tabular}

\begin{tabular}{|c|c|c|}
\hline Aerobic Cometabolism & $\mathrm{ACM}$ & $\begin{array}{l}\text { A source of methane or other co-substrates for these } \\
\text { reactions that is migrating into an aerated portion of the } \\
\text { aquifer needs to be present to provide the driving force } \\
\text { for these reactions. }\end{array}$ \\
\hline Aerobic Direct Metabolism & ADM & No additional information is needed. \\
\hline Abiotic Hydrolysis & $\mathrm{AH}$ & $\begin{array}{l}\text { Confirm temperature and } \mathrm{pH} \text { for use of half-life values in } \\
\text { figures and to adjust as needed based on root data and } \\
\text { equations in noted references. }\end{array}$ \\
\hline Anaerobic Cometabolism & ANCM & $\begin{array}{l}\text { This type of reaction typically occurs with denitrification. } \\
\text { Thus, evidence of active denitrification and an energy } \\
\text { source to drive this reaction (e.g., organic acids) is } \\
\text { needed to verify that this reaction is occurring. }\end{array}$ \\
\hline $\begin{array}{l}\text { Anaerobic Direct } \\
\text { Metabolism }\end{array}$ & ANDM & $\begin{array}{l}\text { Anaerobic direct metabolism is typically linked to } \\
\text { utilization of an electron acceptor such as iron. Thus, } \\
\text { evidence of this type of reduction is needed to assess } \\
\text { whether this reaction is occurring. }\end{array}$ \\
\hline Dichloroelimination (biotic) & DC & $\begin{array}{l}\text { This reaction occurs under geochemically reduced } \\
\text { conditions. The specific daughter products produced by } \\
\text { DC should also be present in most cases. Especially } \\
\text { under the anoxic geochemical setting, microcosm tests } \\
\text { with site-specific sediments may be needed to verify this } \\
\text { reaction. }\end{array}$ \\
\hline $\begin{array}{l}\text { Dehydrochlorination } \\
\text { (abiotic) }\end{array}$ & DHC & $\begin{array}{l}\text { Confirm temperature and } \mathrm{pH} \text { for use of half-life values in } \\
\text { figures and to adjust as needed based on root data and } \\
\text { equations in noted references. This reaction may also } \\
\text { be enhanced under geochemically reduced conditions. } \\
\text { Microcosm tests with site-specific sediments may be } \\
\text { needed to verify any enhancement. }\end{array}$ \\
\hline $\begin{array}{l}\text { Reductive Dechlorination } \\
\text { (biotic) }\end{array}$ & $\mathrm{RD}$ & $\begin{array}{l}\text { This reaction occurs under geochemically reduced } \\
\text { conditions. The specific daughter products produced by } \\
\text { RD should also be present in most cases. Especially } \\
\text { under the anoxic geochemical setting, microcosm tests } \\
\text { with site-specific sediments may be needed to verify this } \\
\text { reaction. }\end{array}$ \\
\hline
\end{tabular}




\subsection{Selection of a Reaction Module}

RT3D provides a suite of reaction modules for use in modelling MNA or MNA/EA of the chlorinated solvents listed in Table 2. Figure 14 shows the basic decision process for selecting one of these reaction modules for MNA applications at a specific site, depending on the contaminant group or groups that are present. In the case where chloroethenes only are present, the selection also depends on whether there is enough information and a desire to explicitly model the link between geochemical oxidation/reduction conditions and dechlorination. For MNA/EA sites, chloroethene reductive dechlorination using substrate/biomass-dependent reaction rates or cometabolic dechlorination can be selected to model the impact of substrates and electron donors on dechlorination. The RT3D reaction modules in Figure 14 are briefly described in Table 5 and are described in detail in Johnson and Truex [2006].

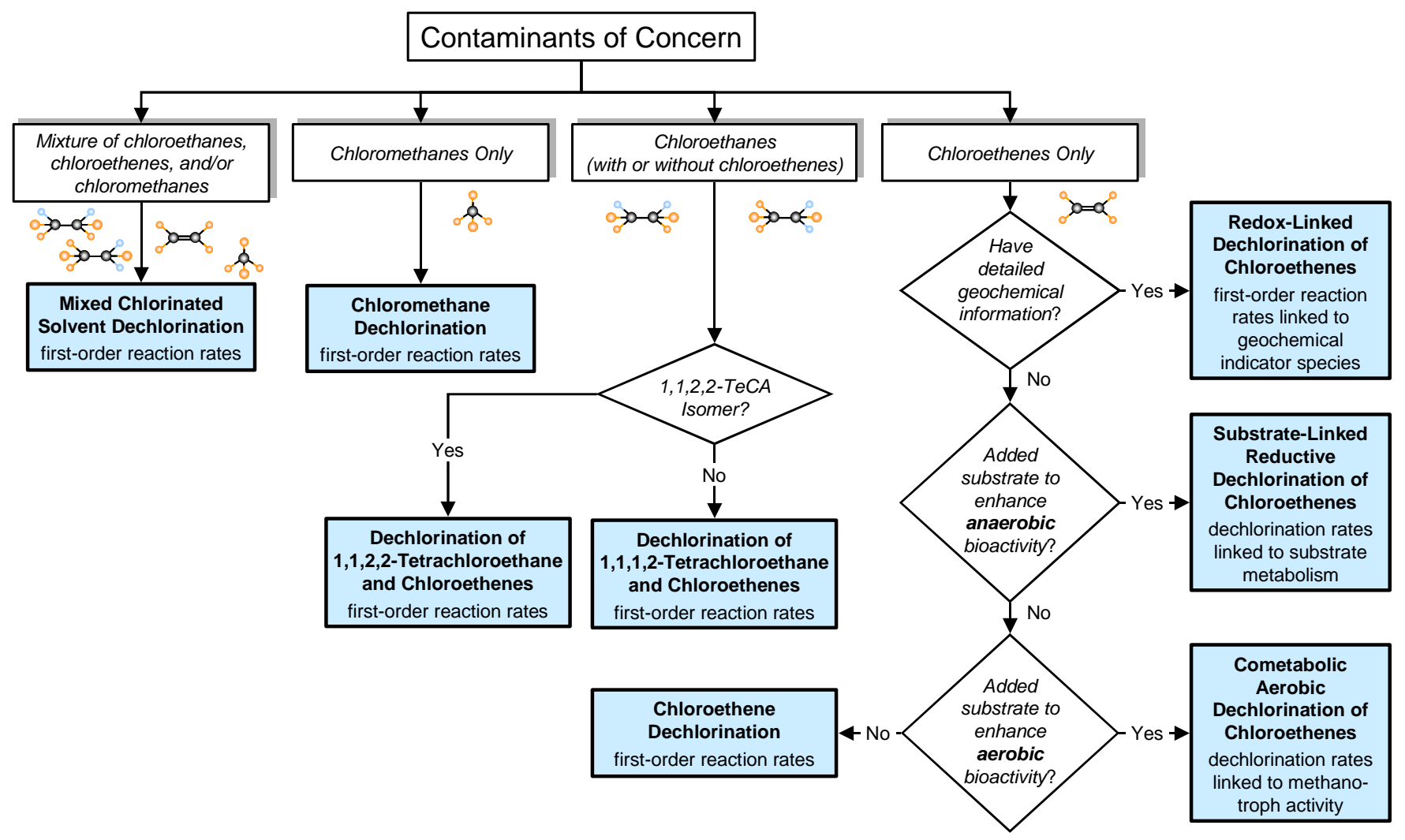

Figure 14. Flowchart for Selection of RT3D Reaction Modules for MNA/EA 
Table 5. Description of the RT3D Reaction Modules for MNA/EA

\begin{tabular}{|c|c|}
\hline Reaction Module Name & Reaction Module Description \\
\hline $\begin{array}{l}\text { Mixed Chloroethenel } \\
\text { Chloroethanel } \\
\text { Chloromethane } \\
\text { Dechlorination }\end{array}$ & $\begin{array}{l}\text { Dechlorination of a mixture of chloroethene, chloroethane, and } \\
\text { chloromethane compounds using first-order rate expressions. This } \\
\text { reaction module includes aerobic anoxic/anaerobic, and abiotic reactions. }\end{array}$ \\
\hline $\begin{array}{l}\text { Chloromethane } \\
\text { Dechlorination }\end{array}$ & $\begin{array}{l}\text { Dechlorination of chloromethane compounds using first-order rate } \\
\text { expressions. This reaction module includes aerobic anoxic/anaerobic, and } \\
\text { abiotic reactions. }\end{array}$ \\
\hline $\begin{array}{l}\text { Dechlorination of } \\
\text { 1,1,2,2-Tetrachloroethane } \\
\text { and Chloroethenes }\end{array}$ & $\begin{array}{l}\text { Dechlorination of 1,1,2,2-tetrachloroethane and chloroethenes using first- } \\
\text { order rate expressions. Includes 1,1,2-TCA and 1,2-DCA. This reaction } \\
\text { module includes aerobic anoxic/anaerobic, and abiotic reactions. }\end{array}$ \\
\hline $\begin{array}{l}\text { Dechlorination of } \\
\text { 1,1,1,2-Tetrachloroethane } \\
\text { and Chloroethenes }\end{array}$ & $\begin{array}{l}\text { Dechlorination of 1,1,1,2-tetrachloroethane and chloroethenes using first- } \\
\text { order rate expressions. Includes 1,1,1-TCA and 1,1-DCA. This reaction } \\
\text { module includes aerobic anoxic/anaerobic, and abiotic reactions. }\end{array}$ \\
\hline $\begin{array}{l}\text { Chloroethene } \\
\text { Dechlorination }\end{array}$ & $\begin{array}{l}\text { Dechlorination of chloroethene compounds using first-order rate } \\
\text { expressions. All DCE isomers are included and additional pathways are } \\
\text { represented over those in other similar RT3D reaction modules. This } \\
\text { module includes aerobic and anoxic/anaerobic reactions (abiotic reactions } \\
\text { are negligible for chloroethenes). }\end{array}$ \\
\hline $\begin{array}{l}\text { Redox-Linked } \\
\text { Dechlorination of } \\
\text { Chloroethenes }\end{array}$ & $\begin{array}{l}\text { Dechlorination of chloroethene compounds using first-order rate } \\
\text { expressions. This module includes aerobic and anoxic/anaerobic } \\
\text { reactions, where the rate of these reactions is controlled by the } \\
\text { oxidation/reduction conditions in the aquifer. Oxygen, nitrate, iron, } \\
\text { sulfate/sulfide, and methane are used as indicator compounds to define } \\
\text { the geochemical conditions. The user may choose to fix the spatial } \\
\text { distribution of the geochemical indicator concentrations or allow the } \\
\text { geochemical indicator compounds to undergo oxidation/reduction to give a } \\
\text { time-varying spatial distribution of geochemical conditions. Note that this } \\
\text { module does not perform full geochemical equilibrium calculations, but } \\
\text { uses indicator species to assess redox conditions. }\end{array}$ \\
\hline $\begin{array}{l}\text { Substrate-Linked } \\
\text { Reductive Dechlorination } \\
\text { of Chloroethenes }\end{array}$ & $\begin{array}{l}\text { Reductive dechlorination of chloroethene compounds using } \\
\text { substrate/biomass-dependent reaction rates. The rates of dechlorination } \\
\text { reactions are dependent on substrate (lactate) consumption and microbial } \\
\text { growth. This is an Enhanced Attenuation reaction module. }\end{array}$ \\
\hline $\begin{array}{l}\text { Cometabolic Aerobic } \\
\text { Dechlorination of } \\
\text { Chloroethenes }\end{array}$ & $\begin{array}{l}\text { Cometabolic dechlorination of TCE, DCE isomers, and VC by } \\
\text { methanotrophic bacteria. The rate of dechlorination is dependent on the } \\
\text { rate of methane consumption and microbial growth. This is an Enhanced } \\
\text { Attenuation reaction module. }\end{array}$ \\
\hline
\end{tabular}


For each reaction module in Table 5, the user determines which reactions are active and provides the appropriate rate coefficients for the reactions. The user sets rate coefficients and/or stoichiometric yields to zero for inactive reactions. Reaction parameters can be spatially variable. For instance, if multiple geochemical settings are identified within the model domain, the rate coefficients in one area can be set to different values than for another area.

RT3D includes two other existing reaction modules potentially of interest to modelling for MNA. These existing reaction modules are not included in Table 5 because they are less detailed. The "Sequential First-Order Decay" and "Aerobic/Anaerobic PCE/TCE Dechlorination" reaction modules were designed for chloroethene dechlorination reactions. The former reaction module is a simple sequential reductive dechlorination module with all DCE isomers lumped as one species and no aerobic or abiotic reactions. While the latter reaction module is similar, but adds aerobic reactions and also tracks chloride as a chemical species. The reaction modules in Table 5 are recommended for application of RT3D simulation to a MNA evaluation, but there may be cases where the simpler reaction modules will suffice.

As mentioned in Section 5.0, additional mechanisms (e.g., non-equilibrium adsorption) or combinations of processes may be assembled in a user-defined reaction module. A user-defined reaction module can be created by writing a Fortran subroutine, possibly using an existing reaction module as a template. The process for developing a user-defined reaction module is described in the RT3D manual [Clement, 1997]. The user-defined reaction module is an extremely flexible tool for combining processes or for adding reaction kinetics for an entirely new set of chemicals (e.g., PCBs or pesticides). 


\subsection{Using a Reaction Module}

Applying a reaction module typically requires 1) an understanding of the site with respect to the reaction processes that may be occurring, 2) appropriately configuring the model with respect to the reaction parameters and inputs that affect the reactions, 3) calibration of the model, and 4) conducting a matrix of simulations that address the modelling objectives for the site to the satisfaction of the stakeholders (e.g., site owners, regulators, technical review). This section describes each of these steps with respect to implementing a reaction module in RT3D.

\subsection{Understanding Site Characteristics With Respect To Reaction Processes That May Be Occurring}

The primary activities associated with identifying what reaction processes may be occurring, and therefore how the site should be modelled, involve assessing the site geochemistry and looking for reaction "signatures". Section 6.0 describes the potential types of reactions that can occur based on categorizing the site into one of three basic geochemical settings. All of the site may fit within one of these settings, or there may different geochemical settings associated with different portions or segments of the site (e.g., near source versus downgradient areas). The following process of categorizing geochemical setting of the site or site segment is based on the approach used in the Scenarios Evaluation Tool for Chlorinated Solvent MNA [Truex et al., 2006]. Table 6 summarizes the criteria used to identify the geochemical setting. All criteria listed in Table 6 for a geochemical category must generally be satisfied for selection of the geochemical setting. The criteria statements and numeric values should not be used as absolute rules. Technical judgment and knowledge of site conditions should be applied in conjunction with these guidelines when determining the site geochemical setting.

Based on the geochemical setting for the site or a segment of the site, the dechlorination reaction information in Section 6.0 can be consulted to determine what reactions may be occurring. For each reaction, specific intermediate and final dechlorination products are produced. These compounds can be used to identify specific reaction signatures for a site and assist in selecting the reactions that should be modelled. Once the set of reactions for a site have been identified, a specific reaction module can be selected based on the module information presented in Section 7.0 . 
Table 6. Criteria for Selecting the Geochemical Setting

Geochemical Setting $\quad$ Description $^{1}$

Average dissolved oxygen concentration $<\sim 1 \mathrm{mg} / \mathrm{L}$ (if meter) or $<\sim 0.5 \mathrm{mg} / \mathrm{L}$ (if test kit);

AND

Sulfate concentration < $50 \mathrm{mg} / \mathrm{L} ; \quad$ (value applies to most but not all sites)

AND

Anaerobic

Nitrate $<\sim 1 \mathrm{mg} / \mathrm{L}$;

AND

Methane OR ferrous iron OR sulfide must be detected in most of the wells;

AND

TOC $>\sim 5 \mathrm{mg} / \mathrm{L}$

AND

Dechlorination daughter products must be present in the plume

Average dissolved oxygen concentration $<\sim 2 \mathrm{mg} / \mathrm{L}$ (by meter or by test kit);

Anoxic AND

Plume doesn't meet all of the anaerobic indicators

Average dissolved oxygen concentration > $\sim 2 \mathrm{mg} / \mathrm{L}$ (by meter or by test kit);

Aerobic

AND

Plume doesn't meet ANY of the anaerobic indicators

${ }^{1}$ Criteria values are for guidance only and technical judgment related to specific site conditions should be used in applying these criteria.

\subsection{Model Configuration}

Once an appropriate reaction package has been selected, the model must be configured properly to use in fate and transport simulations. Configuration of the model with respect to the reaction processes includes 1) determining the appropriate reaction parameter values, 2) determining whether the reaction parameter values need to be spatially variable (e.g., are there multiple zones within the model that will have different reaction processes/rates), and 3) testing/calibration of the reaction module. The following sections discuss these configuration steps.

\subsubsection{Determining Reaction Parameter Values}

Determining the appropriate reaction parameter values to use in the reaction module is one of the most important steps in configuring a fate and transport model. Rate parameter values for hydrolysis reactions are generally not site specific for sites with near neutral $\mathrm{pH}$ conditions and literature values can be directly used for these parameters. However, most reaction parameters, such as the first order rate coefficients for biologically catalyzed reactions and the stoichiometric dechlorination yield, are highly site specific and it is typically not appropriate to use a generic parameter value to apply a reaction module for a specific site. The rate coefficient is dependent on the microbial ecology and geochemistry of the individual site. Likewise, the microbial 
ecology and geochemistry effect the stoichiometric dechlorination yield (e.g., the moles of cis-1,2-DCE and trans-1,2-DCE produced from dechlorination of a mole of TCE). The scientific literature provides guidance about the likely range for these reaction parameter values, but a specific value appropriate to the each site must typically be selected. Site-specific reaction parameters are used for deterministic modelling. Alternatively, stochastic modelling can be applied, but site-specific ranges for parameter values should still be established.

There are several methods available to select a specific reaction parameter value for a specific site. Laboratory microcosm tests can be useful for selecting reaction parameter values because it is not always possible to determine the type of dechlorination attenuation process occurring at a site based on field data. While laboratory studies cannot exactly replicate field conditions, they can approximate field conditions and provide insight into the dechlorination attenuation mechanisms. Absolute rates of attenuation from laboratory studies are typically not expected to represent absolute rates under field conditions (except for some abiotic reactions). However, relative rates, for instance, for parent and daughter product dechlorination and the extent of dechlorination, can be reasonably approximated from laboratory data. Because of the controlled experimental conditions, detailed data analysis to determine the reaction pathways and rates is possible and provides useful information in terms of these relative dechlorination rates. Using this information, the laboratory rates can be adjusted during model calibration to match the available site data.

There are also field tests such as "push-pull" testing that can be used to assess reaction rates under in situ conditions [e.g., Kim et al., 2004]. These tests are similar to laboratory microcosm testing in that the reactions are measured based on the response observed to some specific experimental conditions. However, because the tests are conducted in the field, some of the experimental variables cannot be controlled as tightly as for a laboratory test. This type of testing should be considered for sites where the hydraulic and geochemical conditions are expected to enable sufficient control of the experiments for quantifying the reaction rates.

In a limited number of situations, direct analysis of contaminant concentration data from monitoring wells can be used to quantify reaction parameter values [e.g. U.S. EPA, 2002]. If a sufficient amount of spatial and temporal data is available, inverse modelling techniques as part of model calibration can be used to determine reaction rates. In this method, history matching is used to define the reaction rates that are then used to conduct predictive simulations for determining the future fate and transport of contaminants. In some cases, this type of inverse modelling is combined with information from laboratory microcosm tests or the literature to provide additional confidence in the results.

As an alternative to deterministically determining site-specific reaction parameter values, a range of parameter values can be used within a stochastic simulation process (e.g., a Monte Carlo approach) to address the fate and transport of contaminants in a probabilistic manner. 


\subsubsection{Determining Whether the Reaction Parameter Values Need to be Spatially Variable}

Some sites may have uniform geochemical conditions and a single set of reaction parameters is sufficient to describe reactions for the fate and transport analysis. However, some hydrologic conditions and contaminant distributions lead to variations in geochemical conditions across a site that may induce different types of reactions or different rates of reactions. There are two approaches for addressing this type of variation.

A standard approach for addressing variability in reaction rates/processes is to use the variable reaction parameter function of RT3D and to set up zones within the model (e.g., blocks of grid cells) that have specific reaction parameter values. For instance, one zone may have anaerobic reactions active (e.g., near a source) and a downgradient zone may have aerobic reactions active because site data shows an increase in the dissolved oxygen concentration in this downgradient zone. To implement this approach, the modeler must examine the available geochemical and contaminant data and determine if specific zones of reactions can be identified. The model can then be configured with the appropriate parameter values for each zone.

A less common approach, due to the requirement for a significant amount of data and knowledge of the reaction processes, is to use a reaction module that varies the contaminant transformation rates based on the concentrations of selected geochemical indicators. RT3D offers one reaction module for chloroethene dechlorination based on the concentrations of geochemical indicators. In this module, a simplified geochemical approach (versus a full geochemical model) is used to define the reaction conditions (e.g., aerobic versus anaerobic and the dominant redox conditions) and the corresponding dechlorination behavior. Data for the geochemical indicators can be used to define (e.g., through interpolation) a specific indicator concentration for each of the grid cells such that the model will calculate contaminant transformation rates based on this imposed static distribution of geochemistry data. This approach provides a continuous spatial variability of the reaction rates based on the static spatial distribution of the geochemical indicators. The geochemical indicators can also be allowed to react and change over time if there is sufficient data available to define these rates of reactions. See Johnson and Truex [2006] for details on the reaction module implementing this type of geochemical indicator approach to dechlorination.

\subsubsection{Module Testing/Calibration}

Before proceeding to calibration of the full fate and transport model, it is important to test and calibrate the reaction module. The preceding sections discuss configuring the module based on the site conditions and data available for setting reaction parameters. It is typically useful to run the reaction module in a batch (no flow) mode or with a very simple flow model (e.g., on a simple testing grid with uniform hydraulic and transport conditions) to examine the simulated variation in the constituent concentrations over time and compare these patterns to what is expected based on the available data. In the case where laboratory microcosm tests have been conducted, batch simulations can be used to refine the reaction parameter values and calibrate 
the module to the microcosm data. If less detailed data are available, the testing simulation results can still be examined with respect to the pattern of dechlorination and whether the relative persistence of the expected intermediate compounds matches the basic patterns observed at the site. While this task may seem duplicative to calibration of the full model, it is important to isolate the reaction module functioning so that any problems, including simple user input errors, can be more readily identified. It can be much more difficult to identify issues with the reaction module parameter values when advection, dispersion, and sorption are occurring at the same time within the full fate and transport model.

\subsection{Model Calibration}

When configuring the model, estimates of parameter values for the transport equation terms are established. In many cases, these estimates provide a reasonable range for the value of parameters, but cannot identify a specific correct value for a given site condition. The calibration process is used to seek the best fit of simulation results to a set of observed data available for the site. In this way, the calibration assesses the adequacy of the model in simulating the actual processes at the site. If the model meets expectations for the calibration, a technical basis for use of the model in a predictive mode has been established. Multiple statistically determined simulation scenarios can also be used to produce a range of model outputs for evaluation in contrast to interpretations of a best-fit model output.

To calibrate the model, parameters need to be varied within the acceptable range established in the model configuration and the model results compared to field data. This can be a directed process whereby the modeler sequentially varies parameters to converge on a best-fit solution, based on minimizing the difference between the model output and the field data. Care must be taken in this approach to consider that there may not be a unique set of parameters that define the best fit. However, with appropriate technical judgment, a reasonable best-fit model can be obtained. It is important to examine the parameter values that comprise the best-fit model to determine whether they make sense and to assess the impact of any parameters in the model that do not have a good physical basis (i.e., fitting factors). Prior to use of the model, the technical basis for the model fit needs to be assessed. A sensitivity assessment of the selected parameter values and the impact on the fit of the model is one means to evaluate whether the best fit has been obtained or whether predictive simulations should be conducted using several model configurations rather than just one best fit. It is also possible to use computer optimization routines to conduct the parameter variation testing and determine the best fit by comparison of the model to field data. This process, termed inverse modelling, requires that the comparison can be effectively described in terms of an objective function that the optimization routine can use to assess the suitability of parameter values. Further discussion of the calibration process, comparison to observed data, sensitivity analysis, and inverse modelling is available in a number of documents [e.g., ASTM, 1993; ASTM, 1994; ASTM, 1996; Hill, 1998; U.S. ACE, 1999; Neuman and Wierenga, 2003; Poeter et al., 2005]. 
Calibration of a flow model is typically achieved by variation of the relevant parameters (e.g., the hydraulic conductivity distribution) to match hydraulic head data for the site. Calibration of the flow model precedes calibration of the transport model, but may need to be iteratively adjusted during on the transport model calibration process. Typically, the calibration of the transport model is more difficult because there are more parameters that can impact the results and there are more data for the comparison (e.g., concentrations for multiple contaminant species). Standard groundwater interface packages provide techniques to aid in the calibration process.

\subsection{MNA Modelling}

Interpretation of model results is dependent on the context of how the modelling is being applied. This section discusses model interpretation as it applies to the identified roles of modelling for MNA. The two basic categories for interpretation of modelling results include 1) evaluating the impact of each attenuation process on migration of the plume, and 2) estimating whether the remedy (i.e., MNA or MNA/EA) will meet the remediation goals.

Numerical models have the computational ability to estimate the interaction of multiple processes temporally and spatially for scenarios that would be difficult to assess with analytical methods. Thus, numerical models can provide information to help analyze the relative importance of different fate and transport processes at an individual site. Using a model, multiple simulations can be conducted with variations in the input parameters. By comparing the results of these simulations, the relative importance of specific processes can be assessed. This modelling approach can be implemented with simple single parameter variation or using a statistical approach such as the Monte Carlo process.

Predictive simulations are used to estimate future plume migration under the selected remediation scenario (e.g., MNA/EA) and thereby assess the ability of this remedy to meet remediation goals. In some cases, it is appropriate to select specific simulation scenarios and use the calibrated model to assess whether remediation goals will be met under these selected conditions. Alternatively, the modelling approach may include conducting a statistical series of simulations (e.g., Monte Carlo analysis) to predict the probability for future contaminant distributions.

To aid in interpretation of modelling results, simulation data can be displayed a number of different ways. These display options include 1) concentration contours, 2) transect profiles, 3) time profiles, 4) probability contours for set concentration/risk values, and 5) probability of exceeding a limit at a set Point of Compliance. By conducting multiple simulations of different scenarios, models can provide information to evaluate the relative impact of each scenario in terms of how the output described above is changed and to evaluate the sensitivity of the results to changes in specific parameter values. The results of multiple simulations can be interpreted to assess the uncertainty of the modelling results; that is, assessing how variations in input 
parameter data impact the model results. This uncertainty is important to consider in evaluating whether additional characterization for model input parameters is needed or to evaluate the technical risk of a decision based on the model results for the given level of information about the model inputs and the model configuration/calibration. 


\subsection{References}

\subsection{Numbered References Cited in Reaction Pathway Figures}

1. Bagley, D.M., and J.M. Gossett. 1995. "Chloroform Degradation in Methanogenic Methanol Enrichment Cultures and by Methanosarcina barkeri 227.” Appl. Environ. Microbiol., 61(9):3195-3201.

2. Bouwer, E.J., and P.L. McCarty. 1983a. "Transformations of 1- and 2-Carbon Halogenated Aliphatic Organic Compounds under Methanogenic Conditions.” Appl. Environ. Microbiol., 45(4):1286-1294.

3. Bouwer, E.J., and P.L. McCarty. 1983b. "Transformations of Halogenated Organic Compounds under Denitrification Conditions." Appl. Environ. Microbiol., 45(4):1295-1299.

4. Bradley, P.M., and F.H. Chappelle. 1997. "Kinetics of DCE and VC Mineralization under Methanogenic and Fe(III)-Reducing Conditions." Environ. Sci. Technol., 31(9):2692-2696.

5. Bradley, P.M., and F.H. Chapelle. 2000. "Aerobic Microbial Mineralization of Dichloroethene as Sole Carbon Substrate.” Environ. Sci. Technol., 34(1):221-223.

6. Chang, H., and L. Alvarez-Cohen. 1996. "Biodegradation of Individual and Multiple Chlorinated Aliphatic Hydrocarbons by Methane-Oxidizing Cultures." Appl. Environ. Microbiol., 62(9):3371-3377.

7. Chen, C., J.A. Puhakka, and J.F. Ferguson. 1996. "Transfromations of 1,1,2,2,Tetrachloroethane under Methanogenic Conditions." Environ. Sci. Technol., 30(2):542-547.

8. Culubret, E.N., M. Luz, R. Amils, and J.L. Sanz. 2001. "Biodegradation of 1,1,1,2Tetrachloroethane under Methanogenic Conditions." Water Sci. Technol., 44(4):117-122.

9. DeBruin, W.P., M.J.J. Kotterman, M.A. Posthumus, G. Schraa, and A.J.B. Zehnder. 1992. "Complete Biological Reductive Transformation of Tetrachloroethene to Ethane." Appl. Environ. Microbiol., 58(6):1996-2000.

10. Egli, C., S. Stromeyer, A.M. Cook, and T. Leisinger. 1990. "Transformation of Tetra- and Trichloromethane to $\mathrm{CO} 2$ by Anaerobic Bacteria is a Non-Enzymatic Process." FEMS Microbiol. Letters, 68(1-2):207-212. 
11. Freedman, D.L., and J.M. Gossett. 1989. "Biological Reductive Dechlorination of Tetrachloroethylene and Trichloroethylene to Ethylene under Methanogenic Conditions." Appl. Environ. Microbiol., 55(9):2144-2151.

12. Freedman, D.L., and J.M. Gossett. 1991. "Biodegradation of Dichloromethane and Its Utilization as a Growth Substrate under Methanogenic Conditions." Appl. Environ. Microbiol., 57(10):2847-2857.

13. Freedman, D.L., M. Swamy, N.C. Bell, and M.F. Verce. 2004. "Biodegradation of Chloromethane by Pseudomonas aeruginosa Strain NB1 under Nitrate-Reducing and Aerobic Conditions." Appl. Environ. Microbiol., 70(8):4629-4634.

14. Haag, W.R., and T. Mill. 1988. "Effect of a Subsurface Sediment on Hydrolysis of Haloalkanes and Epoxides." Environ. Sci. Technol., 22(6):658-663.

15. Hartmans, S., and J.A.M. de Bont. 1992. "Aerobic Vinyl Chloride Metabolism in Mycobacterium aurum L1.” Appl. Environ. Microbiol., 58(4):1220-1226.

16. Hunkeler, D., and R. Aravena. 2000. "Evidence of Substantial Carbon Isotope Fractionation Among Substrate, Inorganic Carbon, and Biomass During Aerobic Mineralization of 1,2-Dichloroethane by Xanthobacter autotrophicus." Appl. Environ. Microbiol., 66(11):4870-4876.

17. Jeffers, P.M., L.M. Ward, L.M. Woytowltch, and N.L. Wolfe. 1989. "Homogeneous Hydrolysis Rate Constants for Selected Chlorinated Methanes, Ethanes, Ethenes, and Propanes." Environ. Sci. Technol., 23(8):965-969.

18. Kim, Y., D.J. Arp, and L. Semprini. 2000. "Chlorinated Solvent Cometabolism by ButaneGrown Mixed Culture.” J. Environ. Eng., 126(10):934-942.

19. Kim, Y., D.J. Arp, and L. Semprini. 2002. "Kinetic and Inhibition Studies for the Aerobic Cometabolism of 1,1,1-Trichloroethane, 1,1-Dichloroethylene, and 1,1-Dichloroethane by a Butane-Grown Mixed Culture." Biotechnol. Bioeng., 80(5):498-508.

20. Klier, N.J., R.J. West, and P.A. Donberg. 1998. "Aerobic Biodegradation of Dichloroethylenes in Surface and Subsurface Soils." Chemosphere, 38(5):1175-1188.

21. Leisinger, T., R. Bader, R. Hermann, M. Schmid-Appert, and S. Vuilleumier. 1994. "Microbes, Enzymes and Genes Involved in Dichloromethane Utilization." Biodegradation, 5(3-4):237-248.

22. Mabey, W., and T. Mill. 1978. "Critical Review of Hydrolysis of Organic Compounds in Water under Environmental Conditions." J. Phys. Chem. Ref. Data, 7(2):383-415. 
23. Pagan, M., W.J. Cooper, and J.A. Joens. 1998. "Kinetic Studies of the Homogeneous Abiotic Reactions of Several Chlorinated Aliphatic Compounds in Aqueous Solution." Appl. Geochem., 13(6):779-785.

24. Vannelli, T., A. Studer, M. Kertesz, and T. Leisinger. 1998. "Chloromethane Metabolism by Methylobacterium sp. Strain CM4.” Appl. Environ. Microbiol., 64(5)1933-1936.

25. Vogel, T.M., and P.L. McCarty. 1987. "Abiotic and Biotic Transformation of 1,1,1Trichloroethane under Methanogenic Conditions." Environ. Sci. Technol., 21(12):1208-1213.

\subsection{References Cited in Document}

ASTM. 1993. Standard Guide for Comparing Ground-Water Flow Model Simulations to SiteSpecific Information. D 5490-93 (2002), ASTM International, West Conshohocken, Pennsylvania.

ASTM. 1994. Standard Guide for Conducting a Sensitivity Analysis for a Ground-Water Flow Model Application. D 5611-94 (2002), ASTM International, West Conshohocken, Pennsylvania.

ASTM. 1996. Standard Guide for Calibrating a Ground-Water Flow Model Application. D 5981-96 (2002), ASTM International, West Conshohocken, Pennsylvania.

Ayra, A. 1986. Dispersion and Reservoir Heterogeneity. Ph.D. Dissertation, University of Texas, Austin, Texas.

Barth, G.R., T.H. Illangasekare, M.C. Hill, and H. Rajaram. 2001. "A New Tracer-Density Criterion for Heterogeneous Porous Media.” Water Resour. Res., 37(1):21-31.

Bishop, D.J., J.P. Knezovitch, and D.W. Rice, Jr. 1989. Sorption Studies of VOCs Related to Soil/Ground Water Contamination at LLNL. UCID-21651, Lawrence Livermore National Laboratory, Livermore, California.

Brusseau, M.L., and P.S.C. Rao. 1989. "Sorption Nonideality During Organic Contaminant Transport in Porous Media." Crit. Rev. Environ. Control, 19(1):33-99.

Carroll, K.M., M.R. Harkness, A.A. Bracco, and R.R. Balcarcel. 1994. "Application of a Permeant/Polymer Diffusional Model to the Desorption of Polychlorinated Biphenyls from Hudson River Sediments.” Environ. Sci. Technol., 28(2):253-258.

Chen, W., A.T. Kan, C.J. Newell, E. Moore, and M.B. Tomson. 2002. "More Realistic Soil Cleanup Standards with Dual-Equilibrium Desorption." Ground Water, 40(2):153-164. 
Clement, T.P. 1997. RT3D - A Modular Computer Code for Simulating Reactive Multi-Species Transport in 3-Dimensional Groundwater Aquifers. PNNL-11720, Pacific Northwest National Laboratory, Richland, Washington.

Clement, T.P. 2001. "A Generalized Analytical Method for Solving Multi-Species Transport Equations Coupled with a First-Order Reaction Network." Water Resour. Res., 37(1):157-163.

Clement, T.P., Y. Sun, B.S. Hooker, and J.N. Petersen. 1998. "Modeling Multi-Species Reactive Transport in Groundwater Aquifers." Ground Water Monit. Remed., 18(2):79-92.

Clement, T.P., C.D. Johnson, Y. Sun, G.M. Klecka, and C. Bartlett. 2000. "Natural Attenuation of Chlorinated Ethene Compounds: Model Development and Field-Scale Application at the Dover Site." J. Contam. Hydrol., 42(2-4):113-140.

Clement, T.P., and C.D. Johnson. 2002. RT3D v2.5 Update Document. Pacific Northwest National Laboratory, Richland, Washington. Available online at: $\mathrm{http}: / /$ bioprocess.pnl.gov/rt3d_down.htm\#doc.

Clement, T.P., T.R. Gautam, K.K. Lee, M.J. Truex, and G.B. Davis. 2004a. "Modeling of DNAPL-Dissolution, Rate-Limited Sorption and Biodegradation Reactions in Groundwater Systems.” Bioremed. J., 8(1-2):47-64.

Clement, T.P., Y.C. Kim, T.R. Gautam, and K.K. Lee. 2004b. "Experimental and Numerical Investigation of NAPL Dissolution Processes in a Laboratory Scale Aquifer Model." Ground Water Monit. Remed., 24(4):88-96.

Culver, T.B., S.P. Hallisey, D. Sahoo, J.J. Deitsch, and J.A. Smith. 1997. "Modeling the Desorption of Organic Contaminants from Long-Term Contaminated Soil Using Distributed Mass Transfer Rates.” Environ. Sci. Technol., 31(6):1581-1588.

Early, T., B. Borden, M. Heitkamp, B.B. Looney, D. Major, J. Waugh, G. Wein, T. Wiedemeier, K.M. Vangelas, K.M. Adams, and C.H. Sink. 2006. Enhanced Attenuation: A Reference Guide on Approaches to Increase the Natural Treatment Capacity of a System. WSRC-TR-2005-00198, Rev. 0, Savannah River National Laboratory, Westinghouse Savannah River Company, Aiken, South Carolina.

Farrell, J., and M. Reinhard. 1994. "Desorption of Halogenated Organics Form Model Solids, Sediments, and Soil Under Unsaturated Conditions. 2. Kinetics." Environ. Sci. Technol., 28(1):63-72.

Farrell, J., D. Grassian, and M. Jones. 1999. "Investigation of Mechanisms Contributing to Slow Desorption of Hydrophobic Organic Compounds from Mineral Solids." Environ. Sci. Technol., 33(8):1237-1243. 
Freeze, R.A., and J.A. Cherry. 1979. Groundwater. Prentice-Hall, Inc., Englewood Cliffs, New Jersey.

Gelhar, L.W., C. Welty, and K.R. Rehfeldt. 1992. "A Critical Review of Data on Field-Scale Dispersion in Aquifers." Water Resour. Res., 28(7):1955-1974.

Haggerty, R., and S.M. Gorelick. 1994. "Design of Multiple Contaminant Remediation: Sensitivity to Rate-Limited Mass Transfer." Water Resour. Res., 30(2):435-446.

Harbaugh, A.W., E.R. Banta, M.C. Hill, and M.G. McDonald. 2000. MODFLOW-2000, the U.S. Geological Survey Modular Ground-Water Model - User Guide to Modularization Concepts and the Ground-Water Flow Process. Open-File Report 00-92, United States Geological Survey, Reston, Virginia.

Hill, M.C. 1998. Methods and Guidelines for Effective Model Calibration. WRIR 98-4005, United States Geological Survey, Denver, Colorado.

Jeng, C.Y., D.H. Chen, and C.L. Yaws. 1992. "Data Compilation for Soil Sorption Coefficient." Pollut. Eng., 24(12):54-60.

Johnson, C.D., and J.R. Spencer. 2003. "Modifications to MODFLOW and RT3D for Modelling Cyclic Seasonal Variations in Groundwater Flow." In: Proceedings of Modflow and More 2003: Understanding through Modeling (Volume II), E. Poeter, C. Zheng, M. Hill, and J. Doherty, eds. International Ground Water Modeling Center, Colorado School of Mines, Golden, Colorado. pp. 764-768.

Johnson, C.D., and M.J. Truex. 2006. RT3D Reaction Modules for Natural and Enhanced Attenuation of Chloroethanes, Chloroethenes, Chloromethanes, and Daughter Products. PNNL-15938, Pacific Northwest National Laboratory, Richland, Washington.

Karickhoff, S.W., D.S. Brown, and T.A. Scott. 1979. "Sorption of Hydrophobic Pollutants on Natural Sediments." Water Res., 13(3):241-248.

Kile, D.E., C.T. Chiou, H. Zhou, H. Li, and O. Xu. 1995. "Partition of Nonpolar Organic Pollutants from Water to Soil and Sediment Organic Matters." Environ. Sci. Technol., 29(5):1401-1406.

Kim, Y., J.D. Istok, and L. Semprini. 2004. "Push-Pull Tests for Assessing In Situ Aerobic Cometabolism." Ground Water, 42(3):329-337.

Klute, A., and C. Dirksen. 1986. "Hydraulic Conductivity and Diffusivity: Laboratory Methods." In: Klute, A., ed. Methods of Soil Analysis, Part 1 - Physical and Mineralogical Methods, second edition. American Society of Agronomy, Inc., Soil Science Society of America, Inc., Madison, Wisconson. pp. 687-734. 
Kruseman, G.P., and N.A. de Ridder. 1990. Analysis and Evaluation of Pumping Test Data. Publication 47, International Institute for Land Reclamation and Improvement, Wageningen, The Netherlands.

Lyman, W.J., W.F. Reehl, and D.H. Rosenblatt, eds. 1990. Handbook of Chemical Property Estimation Methods. American Chemical Society, Washington, D.C.

Miller, C.T., G. Christakos, P.T. Imhoff, J.F. McBride, J.A. Pedit, and J.A. Trangenstein. 1998. "Multiphase Flow and Transport Modeling in Heterogenous Porous Media: Challenges and Approaches." Adv. Water Resour., 21(2):77-120.

Miller, C.T., M.M. Poirier-McNeill, and A.S. Mayer. 1990. "Dissolution of Trapped NonAqueous Phase Liquids: Mass Transfer Characteristics." Water Resour. Res., 26(11):2783-2796.

Neuman, S.P. 1990. "Universal Scaling of Hydraulic Conductivities and Dispersivities in Geologic Media." Water Resour. Res., 26(8):1749-1758.

Neuman, S.P., and P.J. Wierenga. 2003. A Comprehensive Strategy of Hydrogeologic Modeling and Uncertainty Analysis for Nuclear Facilities and Sites. NUREG/CR-6805, United States Nuclear Regulatory Commission, Office of Nuclear Regulatory Research, Washington, D.C.

Pedit, J.A., and C.T. Miller. 1994. "Heterogeneous Sorption Processes in Subsurface Systems, 1. Model Formulations and Applications." Environ. Sci. Technol., 28(12):2094-2104.

Perfect, E., M.C. Sukop, and G.R. Haszler. 2002. "Prediction of Dispersivity for Undisturbed Soil Columns from Water Retention Parameters." Soil Sci. Soc. Am. J., 66(3):696-701.

Pickens, J.F., and G.E. Grisak. 1981. "Scale-Dependent Dispersion in a Stratified Granular Aquifer." Water Resour. Res., 17(4):1191-1211.

Poeter, E.P., M.C. Hill, E.R. Banta, S. Mehl, and S. Christensen. 2005. UCODE_2005 and Six Other Computer Codes for Universal Sensitivity Analysis, Calibration, and Uncertainty Evaluation. Techniques and Methods 6-A11, United States Geological Survey, Reston, Virginia.

Powers, S.E., C.E. Loureiro, L.M. Abriola, and W.J. Weber, Jr. 1991. "Theoretical Study of the Significance of Non-Equilibrium Dissolution of Non-Aqueous Phase Liquids in Subsurface Systems.” Water Resour. Res., 27(4):463-477.

Powers, S.E., L.M. Abriola, and W.J. Weber, Jr. 1994. “An Experimental Investigation for Non Aqueous Phase Liquid Dissolution in Saturated Subsurface Systems: Transient Mass Transfer Rates.” Water Resour. Res., 30(2):321-332. 
Quezada, C.R., C.M. Hansen, T.P. Clement, N.L. Jones, and K.K. Lee. 2003. "ART3D- An Analytical Model for Predicting 3-Dimensional Reactive Transport." In: Proceeding of the MODFLOW and More 2003: Understanding Through Modelling, Golden, Colorado, September 17-19, 2003. International Ground Water Modelling Center, Colorado School of Mines, Golden, Colorado.

Quezada, C.R., T.P. Clement, and K.K. Lee. 2004. "Generalized Solution to MultiDimensional, Multi-Species Transport Equations Coupled with a First-Order Reaction Network Involving Distinct Retardation Factors." Adv. Water Resour., 27(5):507-520.

Rugner, H., S. Kleineidam, and P. Grathwohl. 1999. "Long Term Sorption Kinetics of Phenathrene in Aquifer Materials." Environ. Sci. Technol., 33(10):1645-1651.

Russell, H.H., J.E. Matthews, and G.W. Sewell. 1992. EPA Ground Water Issue: TCE Removal from Contaminated Soil and Ground Water. EPA/540/S-92/002, United States Environmental Protection Agency, Office of Solid Waste and Emergency Response, Washington D.C.

Simmons, C.T. 2005. "Variable Density Groundwater Flow: From Current Challenges to Future Possibilities." Hydrogeol. J., 13(1):116-119.

Simpson, M.J., K.A. Landman, and T.P. Clement. 2005. "Assessment of a Non-Traditional Operator Split Algorithm for Simulation of Reactive Transport." Math. Comp. Sci. Simulat., 70(1):44-60.

Smith, A.J., and J.V. Turner. 2001. "Density-Dependent Surface Water-Groundwater Interaction and Nutrient Discharge in the Swan-Canning Estuary." Hydrol. Process., 15(13):2595-2616.

Stephanatos, B.N., K. Water, A. Funk, and A. MacGregor. 1991. "Pitfalls Associated with the Assumption of a Constant Partition Coefficient in Modeling Sorbing Solute Transport Through the Subsurface." In: Proceedings of the International Symposium on Ground Water, American Society of Civil Engineers (ASCE), Nashville, Tennessee, July 29-August 2, 1991. American Society of Civil Engineers, New York. pp. 13-20.

Truex, M.J., C.J. Newell, B.B. Looney, and K.M. Vangelas. 2006. Scenarios Evaluation Tool for Chlorinated Solvent Monitored Natural Attenuation. WSRC-STI-2006-00075, Savannah River National Laboratory, Washington Savannah River Company, Aiken, South Carolina.

U.S. ACE. 1999. Engineering and Design: Groundwater Hydrology. EM 1110-2-1421, United States Army Corps of Engineers, Washington, D.C. 
U.S. EPA. 1998. Technical Protocol for Evaluating Natural Attenuation of Chlorinated Solvents in Ground Water. EPA/600/R-98/128, United States Environmental Protection Agency, Office of Research and Development, Washington D.C.

U.S. EPA. 1999a. Use of Monitored Natural Attenuation at Superfund, RCRA Corrective Action, and Underground Storage Tank Sites. OSWER Directive number 9200.4-17P, United States Environmental Protection Agency, Office of Solid Waste and Emergency Response, Washington, D.C.

U.S. EPA. 1999b. BIOCHLOR - Natural Attenuation Decision Support System v1.0. User's Manual. EPA/600/R-00/008, United States Environmental Protection Agency, Office of Research and Development, Washington, D.C.

U.S. EPA. 2002. Calculation and Use of First-Order Rate Constants For Monitored Natural Attenuation Studies. EPA/540/S-02/500, United States Environmental Protection Agency, Washington, D.C.

Werth, C.J., S.A. McMillan, and H.J. Castilla. 2000. " "Structural Evaluation of Slow Desorbing Sites in Model and Natural Solids Using Temperature Stepped Desorption Profiles. 1. Model Development.” Environ. Sci. Technol., 34(14):2959-2965.

Westbrook, S.J., J.L. Rayner, G.B. Davis, T.P. Clement, P.L. Bjerg, and S.J. Fisher. 2005. "Interaction between shallow groundwater, saline surface water and contaminant discharge at a seasonally and tidally forced estuarine boundary." J. Hydrol., 302(1-4):255-269.

Wood, M., C. T. Simmons, and J. L. Hutson. 2004. "A Breakthrough Curve Analysis of Unstable Density-Driven Flow and Transport in Homogeneous Porous Media." Water Resour. Res., 40(3):W03505/1-9.

Xu, M., and Y. Eckstein. 1995. "Use of Weighted Least Squares Method in Evaluation of the Relationship Between Dispersivity and Field-Scale.”" Ground Water, 33(6):905-908.

Xu, M., and Y. Eckstein. 1997. "Statistical Analysis of the Relationships Between Dispersivity and Other Physical Properties of Porous Media." Hydrogeology J., 5(4):4-20.

Zheng, C., and P.P. Wang. 1999. MT3D: A Modular Three-Dimensional Multispecies Transport Model - Documentation and User's Guide. SERDP-99-1, United States Army Corps of Engineers, Engineer Research and Development Center, Vicksburg, Mississippi. Available online at: http://hydro.geo.ua.edu/mt3d.

Zheng, C., M.C. Hill, and P.A. Hsieh. 2001. Modflow-2000, the U.S. Geological Survey Modular Ground-Water Model - User Guide to the LMT6 Package, the Linkage with MT3DMS for Multi-Species Mass Transport Modeling. Open-File Report 01-82, United States Geological Survey, Denver, Colorado. 
PNNL-15937

\section{Distribution}

No. of

$\underline{\text { Copies }}$

OFFSITE

1 T.P. Clement

Auburn University

Department of Civil Engineering

212 Harbert Engineering Center

Auburn, AL 36849-5337

1 B.B. Looney

Savannah River National Laboratory

Bldg. 773-42A

Aiken, SC 29808

1 C.J. Newell

Groundwater Services, Inc.

2211 Norfolk, Suite 1000

Houston, TX 77098-4054

$1 \quad$ K.M. Vangelas

Savannah River National Laboratory

Bldg. 773-42A

Aiken, SC 29808
No. of

Copies

ONSITE

6 Pacific Northwest National Laboratory

T.J. Gilmore

K6-96

C.D. Johnson (2)

K6-96

M.J. Truex

K6-96

Information Release Office (2) P8-55

Distr.1 